$5-9-2015$

\title{
Dynamic Adverse Selection: Time-Varying Market Conditions and Endogenous Entry
}

Pavel Zryumov

Follow this and additional works at: https://repository.upenn.edu/fnce_papers

Part of the Finance and Financial Management Commons

\section{Recommended Citation}

Zryumov, P. (2015). Dynamic Adverse Selection: Time-Varying Market Conditions and Endogenous Entry. Retrieved from https://repository.upenn.edu/fnce_papers/24 


\title{
Dynamic Adverse Selection: Time-Varying Market Conditions and Endogenous Entry
}

\begin{abstract}
In this paper I analyze the effects of time-varying market conditions and endogenous entry on the equilibrium dynamics of markets plagued by adverse selection. I show that variation in gains from trade, stemming from market conditions, creates an option value and distorts liquidity when gains from trade are low. An improvement in market conditions triggers a wave of high-quality deals due to the preceding illiquidity and lack of incentives to signal quality. When gains from trade are high, the market is fully liquid; high prices and no delay in trade attract low-grade assets, and the average quality deteriorates. My analysis also reveals that illiquidity can act as a remedy as well as a cause of inefficiency: partial illiquidity allows for screening of assets and restores efficient entry incentives. I demonstrate model implications using several applications: early stage financing, initial public offerings, and private equity buyouts.

\section{Disciplines}

Finance and Financial Management
\end{abstract}




\title{
Dynamic Adverse Selection: Time-Varying Market Conditions and Endogenous Entry*
}

\author{
Job Market Paper \\ Pavel Zryumov ${ }^{\dagger}$ \\ Graduate School of Business \\ Stanford University
}

May $9,2015^{\ddagger}$

\begin{abstract}
In this paper I analyze the effects of time-varying market conditions and endogenous entry on the equilibrium dynamics of markets plagued by adverse selection. I show that variation in gains from trade, stemming from market conditions, creates an option value and distorts liquidity when gains from trade are low. An improvement in market conditions triggers a wave of high-quality deals due to the preceding illiquidity and lack of incentives to signal quality. When gains from trade are high, the market is fully liquid; high prices and no delay in trade attract low-grade assets, and the average quality deteriorates. My analysis also reveals that illiquidity can act as a remedy as well as a cause of inefficiency: partial illiquidity allows for screening of assets and restores efficient entry incentives. I demonstrate model implications using several applications: early stage financing, initial public offerings, and private equity buyouts.
\end{abstract}

*I thank my advisors Andrzej Skrzypacz and Ilya Strebulaev for numerous lengthy discussions, valuable feedback, continuous support, and encouragement. I would also like to thank Peter DeMarzo, Steven Grenadier, and participants in the Stanford GSB Research Seminar for many constructive comments.

${ }^{\dagger}$ Email: pzryumov@stanford.edu, phone: +1 (650) 391-71-84.

†The latest version is available at http://stanford.edu/ ${ }^{\sim}$ pzryumov 


\section{Introduction}

Adverse selection is an important feature of financial markets. Recently, substantial progress has been made to understand dynamic adverse selection and study adverse selection in richer environments ${ }^{1}$. The general finding of this research is that, unlike in the classic Akerlof (1970) model, trade does not necessarily break down. Owners of higher quality assets can signal the quality by accepting either a lower probability of trade (Chang (2011), Guerrieri and Shimer (2014)) or longer waiting times (Daley and Green (2012), Fuchs and Skrzypacz (2014)) in return for higher prices. While the possibility to signal higher asset quality allows for all assets to be eventually traded, trade is inefficiently delayed.

The markets that involve dynamic adverse selection commonly share two important features that have not been explored in the literature. First, the quality of assets that enter the market is endogenous and is affected by the evolution of beliefs. Consider, for example, a market for early stage financing of high-growth firms, provided by venture capital (VC) or angel investors. When deciding whether to pursue an innovative idea, a potential entrepreneur evaluates the private cost of quitting a job or dropping out of college against a potential benefit of working on a startup. This decision is strongly influenced by the prevailing prices in the market for venture and angel capital, as well as the time it takes to raise the funds. The potential entrepreneur enters the market for funding after observing how "hot" the market is. In other words, the decision to enter the funding market is strategic and depends not only on the quality of the idea but also on current market conditions. These strategic decisions affect the average project quality in the market and cause a feedback loop leading to adjustments in prices and incentives to signal quality.

Second, the markets are characterized by the time variation of market conditions. In early stage financing, the cost of VC funding varies over time for reasons unrelated to the supply of innovative ideas. Gompers and Lerner (2000) and Diller and Kaserer (2009) show that higher capital inflows to the VC industry raise valuations of young ventures regardless of their quality, lowering the cost of funding for entrepreneurs. Varying market conditions create an option for entrepreneurs to optimally time their fund-raising.

In this paper, I incorporate these two features in a model of dynamic adverse selection and explore how endogenous entry and time-varying market conditions impact equilibrium market dynamics. In the context of early stage financing, I analyze the dynamics of the

\footnotetext{
${ }^{1}$ See for example Eisfeldt (2004), Chari, Shourideh and Zetlin-Jones (2010), Tirole (2012), Kurlat (2013); Guerrieri and Shimer (2014), Daley and Green (Forthcoming), Fuchs and Skrzypacz (2014), Strebulaev, Zhu and Zryumov (2014).
} 
average quality of projects receiving funding, resulting patterns in deal volume, and the overall market efficiency. I build a dynamic model of adverse selection in which entrepreneurs, who are privately informed about the quality of their ideas, enter the market over time and attempt to raise funds from uninformed investors. The variation in market conditions is driven by investors' cost of capital, modeled as a discount rate. Investors' discount rate ultimately affects gains from trade and incentives of entrepreneurs to raise funds and enter the market.

Although I use the market for early stage financing as a motivating example, the economic mechanism I examine is quite general. It can manifest itself in multiple markets, in which conditions vary over time and adverse selection plays an important role, such as private equity and IPO markets, among others.

My first key result demonstrates the dynamics of the equilibrium volume of deals. In particular, I find that an improvement in market conditions triggers a wave of deals. The wave is driven by a combination of two factors: accumulation of unfunded projects in the market and subsequent deterioration of incentives to delay fund-raising. Low liquidity, when discount rates are high, is caused by entrepreneurs with good projects who signal their type and attempt to raise funds at higher valuations with a delay. The delay results in a buildup of inventory over time. When the discount rate falls, unfunded entrepreneurs with good projects rush to the market for two reasons. First, the option value of waiting for a lower discount rate disappears. Second, high valuations attract worse projects to the market, which contaminates the pool. Strict preference for immediate trade results in abundance of fund-raising activity.

In contrast to Pástor and Veronesi (2005) and Bustamante (2012), I find that delaying fund-raising results in high average quality of projects being funded at the beginning of the wave (even when compared to raising funds in a "cold" market). This is a consequence of the wave being driven by the incentives of high-quality entrepreneurs. Thus, the "quantity adjustment" (Ritter and Welch (2002)) in my model comes from the top rather than from the bottom of the quality distribution.

My second key result demonstrates the variation in the equilibrium quality of funded projects. I show that during good times, when the supply of capital is high and the discount rate of investors is correspondingly low, entrepreneurs raise funds immediately upon entry. However, and perhaps surprisingly, the average quality of funded projects is relatively low. Conversely, during bad times, when the discount rate of investors is high, the number of low quality entrepreneurs entering the market is low, and the average quality of projects in the 
market is relatively high. Raising funds, however, takes longer on average.

An apparent mismatch between the time it takes to raise funds and the quality of projects in the market is resolved via the following intuition. When investors' discount rate is low, project valuations are high regardless of quality. This reduces the desire of entrepreneurs with good projects to signal their type, implying shorter fund-raising times. At the same time, ease of obtaining funds and high valuations attract a lot of entrepreneurs with low quality projects resulting in the low average quality. High discount rates increase sensitivity of entrepreneurs with good projects to underpricing. This observation, in combination with an option to wait for a lower discount rate, renders low price offers during bad times unattractive. In order to raise funds at higher valuations, entrepreneurs with good projects opt to delay fund-raising. This makes a high pooling price less attractive to entrepreneurs with bad projects and incentivizes some to reduce the waiting time by raising funds at low separating valuations. A resulting increase of the quality of the pool allows investors to offer higher pooling prices in the first place. Difficulty of raising funds and low valuations conditional on the project type reduce entry of entrepreneurs with bad projects and, thus, improve the average quality of projects receiving financing.

Another key result is that illiquidity can be both a source of and a remedy for inefficiency. On the one hand, high liquidity is desirable, because positive net present value (NPV) projects are funded quickly and no value is lost due to time discounting. On the other hand, when funding is raised quickly, prices reflect average (pooling) project quality and fail to reveal private information. The pooling price is an effective subsidy to the entrepreneurs with bad projects. It distorts incentives to enter the market and results in negative NPV projects obtaining funding. Efficient incentives to enter are restored when the discount rate of investors is high. Delay allows investors to partially screen the projects by type. Specifically, equilibrium pay-off to the entrepreneur with a bad project fully reveals her private information, resulting in only positive NPV projects being funded in equilibrium.

My model naturally lends itself to several empirical implications. First, the results demonstrate that volume of deals is positively correlated with gains from trade. Lower gains from trade caused by, for example, a higher cost of investors' capital cause a price adjustment, as well as a quantity adjustment. These outcomes are broadly consistent with the findings by Gompers and Lerner (2000) for venture capital and by Axelson, Jenkinson, Strömberg and Weisbach (2009) for private equity buyouts. My model is also predictive of a wave of deals, which is a definitive feature of the IPO (Ritter and Welch (2002)) and private equity buyout (Kaplan and Stein (1993)) markets. 
Second, the results show that quality of the projects receiving funding is non-monotone with respect to the deal volume and the supply of capital, proxied by investors' discount rate. The quality is at its lowest when the discount rate has been low for a prolonged period of time; it is higher when discount rates are high, and it is the highest early in the fund-raising wave. Empirically, this has been generally supported in several markets. In the context of IPOs, Ritter and Welch (2002) write that "it is conventional wisdom among both academics and practitioners that the quality of firms going public deteriorates as a period of high issuing volume progresses." This is consistent with my findings and is empirically confirmed by Chang, Kim and Shim (2013), who show that firms going public early in hot markets are of higher quality than firms going public later. Similarly, Kaplan and Stein (1993) document that transactions completed in the late 1980's (following a long period of cheap access to debt) were of poorer quality: among the largest buyouts, roughly every third resulted in some form of financial distress with every fourth actually defaulting on debt and filing for Chapter 11.

Lastly, the results demonstrate that fund-raising takes more time when investors' discount rate is high. Moreover, startups that raise funds with a delay receive a better price and are on average of higher quality. This prediction is harder to test empirically, since the time when entrepreneur or firm first enters the market for funding is difficult to observe. For younger firms, however, this naturally leads to implications about the firm's age at the time of receiving financing. For example, one could test whether the age of startups raising Series A (the first round of VC investment) covaries over time with VC fund flows. Specifically, one could test whether older startups are more likely to raise Series A round when VC funding is scarce, and whether they are of higher quality and secure better terms.

\section{$1.1 \quad$ Related Literature}

IPO Waves. IPO waves have attracted a lot of attention both in empirical and theoretical literature (e.g. Alti (2005), Pástor and Veronesi (2005), Yung, Çolak and Wei (2008) Bustamante (2012)). The underlying economic mechanism for the occurrence of the "wave" in my model is very different from what has been reported in the literature. Pástor and Veronesi (2005) and Bustamante (2012) use the real option framework to explain IPO waves. In both models, entrepreneurs withdraw from the market when market conditions decline due to the option of waiting and issuing at better terms later. In these papers, deteriorating market conditions prevent entrepreneurs, ceteris paribus, with worse projects from issuing. Yung, Çolak and Wei (2008) consider a static model of adverse selection. They find that a 
decrease in gains from trade also affects the volume of deals through the lower part of the distribution. In contrast, quantity adjustment in my model is driven by entrepreneurs with better projects withdrawing from the market when conditions (gains from trade) deteriorate, and accelerating fund-raising when market conditions improve. The distinctive feature of my model is the initial increase of the average project quality at the beginning of the wave.

Dynamic Markets for Lemons. My paper contributes to theoretical literature on dynamic markets for lemons. In particular, I follow the line of Swinkels (1999), Daley and Green (2012) and Strebulaev, Zhu and Zryumov (2014) by assuming that investors do not observe previous offers received by entrepreneurs (private offers assumption). Unlike Swinkels (1999), who solves a model in which the lemons condition is not binding, and Daley and Green (2012) and Strebulaev, Zhu and Zryumov (2014), who focus on slow revelation of information, I primarily investigate the interaction between variation in gains from trade and the endogenous quality of entry.

The differences between models with private and public offers have been studied by Horner and Vieille (2009) and Fuchs, Öry and Skrzypacz (2014). In my model, private offers play a crucial role: they do not allow for a complete separation of entrepreneurs with good and bad projects. This leads to cross-subsidization in equilibrium. Cross-sectional distribution of the quality of projects affects the degree of cross-subsidization and has a profound effect on the equilibrium structure. In contrast, in models with public offers, Noldeke and Van Damme (1990) and Guerrieri, Shimer and Wright (2010) show that equilibrium is distribution free and features delay or probabilistic trade even when the asset quality has been inferred to be good.

Similar to Guerrieri, Shimer and Wright (2010), trade in my model can happen at several prices simultaneously and sellers are rationed at higher prices. However, the set of prices offered in equilibrium, as well as the expected time to trade at each particular price, depends on the distribution of the projects in the market and expectations about future evolution of gains from trade and/or quality of entry. In Guerrieri, Shimer and Wright (2010), equilibrium prices are distribution and expectation free, they depend only on buyers' valuations.

The rest of the paper is organized as follows. In section 2, I describe a model with a constant discount rate of investors and endogenous entry. In section 3 , I characterize the steady state equilibrium of that model. In section 4 , I describe a model with a time-varying discount rate and explore its dynamic properties. In section 5, I evaluate several applications and discuss the empirical implications of the model. In section 6, I close with concluding 
remarks. All proofs are in the Appendix.

\section{Model Setup}

In this section I consider a model with a constant discount rate of investors. This assumption is relaxed in Section 4.

\subsection{Lemons Market for Projects}

Projects. The model is set up in continuous time. There is a continuum of potential entrepreneurs indexed by $i \in \mathcal{I}$. Each entrepreneur $i$ comes up with an idea of quality $\theta^{i} \in\{g, b\}$ at time $t^{i}$ and makes a one-time decision whether to start developing the idea (entry decision). In case of a positive entry decision, the idea becomes a project and the entrepreneur loses the "potential" prefix. The project requires investment $I$ for successful completion which can be raised at any time after $t^{i}$. Funds are raised from a competitive market using equity. Both the time of entry $t^{i}$ and the quality of the project $\theta^{i}$ are the entrepreneur's private information. Once investment $I$ is made, the project generates a onetime payment $X_{\theta^{i}}\left(X_{g}>X_{b}>0\right)$ with Poisson intensity $\delta_{X}$. Prior to investment, information about the project quality of entrepreneur $i$ becomes public with intensity $\delta$. Entrepreneurs are risk neutral and discount future payoffs at a rate $\rho$.

Every moment $t \geq t^{i}$ since the time of market entry, each entrepreneur receives private offers from investors. ${ }^{2}$ If offers are unfavorable, the entrepreneur can wait for a better price or information revelation. As soon as funds are raised, entrepreneur $i$ leaves the market.

Investors. There is a continuum of competitive and homogeneous risk-neutral investors who discount future payoffs at rate $r \in(0, \rho)$. Thus, an investor's valuation of a $\theta$ quality project is:

$$
V_{\theta}=\frac{\delta_{X}}{\delta_{X}+r} X_{\theta}
$$

\footnotetext{
${ }^{2}$ An alternative way (leading to the same equilibrium) to specify the model is similar to Guerrieri, Shimer and Wright (2010): at each moment in time there is a continuum of open markets indexed by the price $v$ (offered by investors) and the probability of obtaining funds. Entrepreneur $i$ decides on the minimal acceptable price $v_{t}^{i}$ and participates in all markets with $v \geq v_{t}^{i}$. Recall that in Guerrieri, Shimer and Wright (2010) participation is restricted to a single market. Every instant markets clear from the top down (highest prices to lowest) with entrepreneurs being rationed if the supply of projects exceeds the demand for projects at a particular price.
} 
Payoffs. If investor offers to provide capital in return for a share $I / v$ in project $i$, I will call $v$ investor's valuation of project $i$ or, interchangeably, a price offer. If entrepreneur $i$ decides to accept an offer and raise funds at time $t$ at price $v$, then her expected discounted payoff is:

$$
e^{-\rho\left(t-t^{i}\right)} \frac{\delta_{X}}{\delta_{X}+\rho} X_{\theta^{i}}\left(1-\frac{I}{v}\right),
$$

where $1-\frac{I}{v}$ is the entrepreneur's share of the project and $e^{-\rho\left(t-t^{i}\right)}$ is her discount factor. Let $S_{\theta}$ denote the value of the project of quality $\theta$ to an entrepreneur who decides to wait until full information revelation. When information is revealed, all investors value the project at $V_{\theta}$. Since investors are homogeneous and competitive, they will offer financing at zero expected profit. Thus, an entrepreneur's payoff upon raising funds is $\frac{\delta_{X}}{\delta_{X}+\rho} X_{\theta}\left(1-\frac{I}{\frac{\delta_{X}}{\delta_{X}+r} X_{\theta}}\right)$. Taking expectation with respect to the time of information arrival gives:

$$
S_{\theta}=\frac{\delta}{\delta+\rho} \frac{\delta_{X}}{\delta_{X}+\rho} X_{\theta}\left(1-\frac{I}{\frac{\delta_{X}}{\delta_{X}+r} X_{\theta}}\right)
$$

I assume that regardless of the project's quality, it is profitable to raise funds conditional on entry.

Assumption 1. The parameters of the model satisfy:

$$
\frac{\delta_{X}}{\delta_{X}+\rho} X_{\theta}>I \quad \theta \in\{g, b\} .
$$

Let $B_{\theta}(v)$ denote the expected payoff to an entrepreneur with a $\theta$ quality project raising funding at a price $v$ immediately upon entry:

$$
B_{\theta}(v)=\frac{\delta_{X}}{\delta_{X}+\rho} X_{\theta}\left(1-\frac{I}{v}\right) .
$$

\subsection{Entry of Entrepreneurs}

Entrepreneurs arrive to the market starting at time 0. I assume that the supply of entrepreneurs with bad projects is more sensitive to the market conditions than the supply of good projects. In particular, I make the following simplifying assumption: potential entrepreneurs with good ideas always enter the market as soon as they have an idea. Without loss of generality, I can normalize the rate of entry of entrepreneurs with good projects to $1 d t$ (i.e., at time $t$ the total number of entrepreneurs with good projects who enter the market 


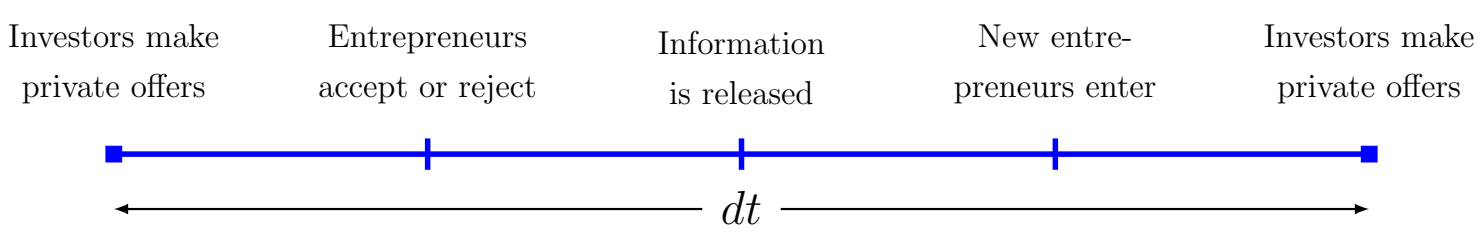

Figure 1: Sequence of events during interval $d t$

is $t)$.

Entrepreneurs with bad projects are strategic about the entry decision. Their entry is affected by the valuations prevalent in the market and the ease of obtaining funding. Every potential entrepreneur $i$ with quality $\theta^{i}=b$ at time $t^{i}$ weighs the benefits from entering the market against a private cost $c^{i}$. The private cost can be interpreted broadly as an opportunity cost of engaging in some other activity (e.g., the cost of quitting a job or dropping out of college). Denote by $G(c)$ the measure ${ }^{3}$ of entrepreneurs with bad projects having private cost no greater than $c$. I assume that $G(\cdot)$ is continuous, strictly increasing with $G(0)=0$ and $G(\infty)=\infty$. Denote by $c_{t}$ the highest private cost of a potential entrepreneur with a bad idea willing to enter the market at time $t$, then $G\left(c_{t}\right) d t$ is the rate of entry of entrepreneurs with bad projects at time $t$.

\section{3 $\quad$ Strategies}

Investors. Instead of defining investors' information sets, strategies, and payoffs, I model them as a collection of stochastic processes $V=\left(V^{i}\right)_{i \in \mathcal{I}}$ with each $V^{i}=\left(V_{t}^{i}\right)_{t \geq 0}$. $V_{t}^{i}$ denotes the highest valuation of entrepreneur's $i$ project at time $t$ conditional on information about project $i$ not being released yet. ${ }^{4}$ The stochastic component in the definition of the price process is needed to allow investors to play mixed strategies, which will be crucial for equilibrium construction. The class of processes that I consider (see Definition 4 in the Appendix) allows for playing a pure strategy, mixing between different prices with positive probabilities, and between prices with positive rates. ${ }^{5}$

To reflect the information available to investors, I impose restrictions on the price processes in Assumption 2.

\footnotetext{
${ }^{3}$ For a precise definition of the index set $\mathcal{I}$, distribution of private $\operatorname{costs} c^{i}$, and distribution of potential entry times $t^{i}$ see Appendix A.

${ }^{4}$ Recall that when information about the project quality is released, the project is priced at $\frac{\delta_{X}}{\delta_{X}+r} X_{\theta^{i}}$ and the entrepreneur raises funds immediately.

${ }^{5}$ The latter strategy, for example, could be used for offering high prices with an exponential delay, similar to arrival of jumps in a Poisson process.
} 
Assumption 2. The collection of price offers $V=\left(V^{i}\right)_{i \in \mathcal{I}}$ satisfies:

1. Private Offers:

$$
\left\{V_{s}^{i} ; s<t\right\} \text { is independent from }\left\{V_{s}^{i} ; s \geq t\right\} \quad \forall i \in \mathcal{I}, t \geq t^{i}
$$

\section{Anonymity:}

$$
\left\{V^{i}\right\}_{i \in \mathcal{I}} \text { are pairwise i.i.d. }
$$

Part 1 of Assumption 2 captures the notion that investors do not observe previous offers received by entrepreneur $i$. Therefore, they cannot condition their current and future offers on that information. Part 2 implies that investors cannot condition their offers on the identity of the entrepreneur (recall that $t^{i}$ is entrepreneur's private information). It also allows me to use the exact law of large numbers in the cross-section of entrepreneurs (i.e., if investors mix between valuations $v_{1}$ and $v_{2}$ with equal probability then exactly half the population of entrepreneurs will be offered $v_{1}$ with the other half being offered $\left.v_{2}\right){ }^{6}$ It is useful to denote the set of all offered valuations at time $t$ as $\mathcal{V}_{t}=\operatorname{supp}\left(V_{t}^{i}\right)$.

Entrepreneurs. At time $t$, potential entrepreneurs with bad ideas and $t^{i}=t$ face an entry decision, which is captured by $c_{t}$ — the highest private cost of entrepreneur who is willing to enter at time $t$. Conditional on entry, each entrepreneur $i$ observes all previously received offers. Hence, her private history is $\mathcal{H}_{t}^{i}=\left\{V_{u}^{i} ; t^{i} \leq u \leq t\right\}$. In order to allow for mixing, I define entrepreneur's strategy $F^{i}$ as a non-decreasing cádlág stochastic process $F^{i}=\left(F_{t}^{i}\right)_{t \geq t^{i}}$ adapted to private history $\left(\mathcal{H}_{t}^{i}\right)_{t \geq t^{i}}$ such that $0 \leq F_{t}^{i} \leq 1$ for all $t \geq t^{i}$. Intuitively, $F_{t}^{i}$ is a cumulative probability of entrepreneur $i$ raising funds before or at time $t$. Every strategy $F^{i}$ induces a (possibly stochastic) time of trade for entrepreneur $i$ which is denoted by $\tau^{i}$. Let $F=\left(F^{i}\right)_{i \in \mathcal{I}}$ denote the strategy profile of all entrepreneurs.

\subsection{Market Belief}

Since investors do not observe either the quality of the projects they are evaluating or the time any particular entrepreneur has been on the market, they form beliefs based on aggregate quantities. Denote by $m_{t}^{g}\left(m_{t}^{b}\right)$ the mass of sellers with good (bad) projects in the market at time $t$. Then:

\footnotetext{
${ }^{6}$ See Sun (2006) for additional detail.
} 


$$
\begin{aligned}
& m_{t}^{g} \equiv \operatorname{mes}\left\{i: t^{i} \leq t \leq \tau^{i} \text { and } \theta^{i}=g\right\} \\
& m_{t}^{b} \equiv \operatorname{mes}\left\{i: t^{i} \leq t \leq \tau^{i} \text { and } \theta^{i}=b \text { and } c^{i} \leq c_{t^{i}}\right\}
\end{aligned}
$$

Let $\pi_{t}$ denote the average aggregate quality of assets in the market at time $t$, then: ${ }^{7,8}$

$$
\pi_{t}= \begin{cases}\frac{m_{t-}^{g}}{m_{t-}^{g}+m_{t-}^{b}}, & \text { if } m_{t-}^{g}+m_{t-}^{b}>0 \\ \frac{1}{1+G\left(c_{t}\right)}, & \text { if } m_{t-}^{g}+m_{t-}^{b}=0\end{cases}
$$

Although I do not model the matching of investors and entrepreneurs explicitly, one can think of investors meeting a random entrepreneur every period $t$ with every entrepreneur meeting at least two investors. If there are currently $m_{t-}^{g}$ entrepreneurs with good projects in the market and $m_{t-}^{b}$ entrepreneurs with bad projects in the market, then the chances that a randomly picked entrepreneur has a good project is $m_{t-}^{g} /\left(m_{t-}^{g}+m_{t-}^{b}\right)$. If, however, all the projects in the past have already received funding $\left(m_{t-}^{g}+m_{t-}^{b}=0\right)$, then the quality of a randomly picked project in the market equals the average quality of the new projects entering the market, $1 /\left(1+G\left(c_{t}\right)\right)$.

\subsection{Equilibrium}

Every entrepreneur $i$ entering the market at time $t^{i}$ maximizes

$$
\sup _{F^{i}} \mathrm{E}\left[S_{\theta^{i}}+\int_{t^{i}}^{\infty} e^{-(\rho+\delta)\left(\tau-t^{i}\right)}\left(B_{\theta^{i}}\left(V_{\tau}^{i}\right)-S_{\theta^{i}}\right) d F_{\tau}^{i}\right] .
$$

One can think of the expected value of investment post information arrival $S_{\theta^{i}}$ as an outside option that an entrepreneur is endowed with at date $t^{i}$. If funds are raised at valuation $V_{\tau}^{i}$ at time $\tau$, then she receives the value $B_{\theta^{i}}\left(V_{\tau}^{i}\right)$ but loses the option $S_{\theta^{i}}$. This payoff is discounted by $e^{-\rho\left(\tau-t^{i}\right)}$ due the entrepreneur's time preferences and by $e^{-\delta\left(\tau-t^{i}\right)}$ due to the possibility of information arrival before time $\tau$. Finally, the expectation is taken over all times $\tau$, which have a cumulative distribution function, $F^{i}$.

For $t \geq t^{i}$, denote by $W_{t}^{i}$ entrepreneur $i$ 's continuation value conditional on the observed

\footnotetext{
${ }^{7}$ As usual, $m_{t-}^{\theta}$ stands for the left limit of $m^{\theta}$ at time $t$ (i.e., $m_{t-}^{\theta} \equiv \lim _{s \uparrow t} m_{s}^{\theta}$ ).

${ }^{8}$ The second part of equation (6) requires conditioning on measure zero set in $\mathcal{I}$. Such conditional expectation is well defined due to Radon-Nikodym.
} 
private history $\mathcal{H}_{t}^{i}$ and the fact that she has not raised funds yet:

$$
W_{t}^{i}=\sup _{F^{i}} \mathrm{E}\left[S_{\theta^{i}}+\int_{t}^{\infty} e^{-(\rho+\delta)(\tau-t)}\left(B_{\theta^{i}}\left(V_{\tau}^{i}\right)-S_{\theta^{i}}\right) d F_{\tau}^{i} \mid \mathcal{H}_{t}^{i}, \tau^{i}>t\right] .
$$

Define two auxiliary processes:

$$
W_{t}^{g}=\sup _{i: t^{i} \leq t, F_{t-}^{i}<1, \theta^{i}=g} W_{t}^{i} \quad \text { and } \quad W_{t}^{b}=\inf _{i: t^{i} \leq t, F_{t-}^{i}<1, \theta^{i}=b} W_{t}^{i}
$$

$W_{t}^{g}\left(W_{t}^{b}\right)$ is the highest (lowest) continuation value of all entrepreneurs with good (bad) projects who are present in the market at time $t$ with positive probability.

Definition 1. An equilibrium is a quadruple $\left(F, V, m^{g}, m^{b}\right)$ with induced continuation values $\left(W_{t}^{g}, W_{t}^{b}\right)$ that satisfy:

1. Seller Optimality: Given $V^{i}, F^{i}$ solves entrepreneur's problem (7) for all $i$ and $t \geq t^{i}$. The entry cut-off is given by:

$$
c_{t}=W_{t}^{b}
$$

\section{Buyer Optimality:}

(a) Zero Profit: For any valuation $v \in \mathcal{V}_{t}$ offered at time $t$, either there does not exist $i$ such that $\tau^{i}=t$ and $V_{t}^{i}=v$, or

$$
v=\frac{\delta_{X}}{\delta_{X}+r} E\left(X_{\theta^{i}} \mid V_{t}^{i}=v, \tau^{i}=t\right)
$$

(b) Market Clearing: ${ }^{9}$

$$
W_{t}^{g} \geq B_{g}\left(\frac{\delta_{X}}{\delta_{X}+r}\left(\pi_{t} X_{g}+\left(1-\pi_{t}\right) X_{b}\right)\right) \quad \text { and } \quad W_{t}^{b} \geq B_{b}\left(\frac{\delta_{X}}{\delta_{X}+r} X_{b}\right)
$$

3. Belief Consistency: Investors' beliefs about the proportion of good quality projects in the market is consistent with $m^{g}$ and $m^{b}$ induced by the entry of new projects (characterized by the entry cut-off $c_{t}$ ) and fund raising decisions induced by the entrepreneurs' strategy $F$ and offered prices $V$.

\footnotetext{
${ }^{9}$ This condition prevents the existence of out-of-equilibrium price offers that would yield positive profits to investors. It is similar to the no deals restriction of Daley and Green (2012) and the market clearing restriction of Fuchs and Skrzypacz (2014).
} 
The first part of the market clearing condition states that the (highest) expected continuation value of an entrepreneur with a good project should be greater or equal than the average quality of all the projects in the market. If at some point expected continuation value falls below the average quality of projects in the market, any investor could make profit by picking a random project and offering a valuation slightly below the market average. Similarly, if (the lowest) continuation value of the entrepreneur with a bad project falls below $B_{b}\left(\frac{\delta_{X}}{\delta_{X}+r} X_{b}\right)$, then a price offer $\frac{\delta_{X}}{\delta_{X}+r} X_{b}-\varepsilon$ would ensure profits with positive probability since it would attract entrepreneurs with bad projects.

Remark 1. Although I model an environment with an entrepreneur (firm) raising a fixed amount of funds by issuing equity, the model is rich enough to incorporate other setups. Consider, for example, a market in which sellers who are privately informed about the quality of the assets (such as pools of mortgages or high-yield corporate bonds) sell to uninformed competitive buyers. Suppose that for (unmodeled) reasons such as liquidity or hedging risks, the seller's value of holding the $\theta$ quality asset ad infinitum, $S_{\theta}$, is smaller than the buyer's value of holding the asset ad infinitum, $V_{\theta}>S_{\theta}$. When a seller transacts at time $t$ at price $v$, she receives $B_{\theta}(v)=v$, but loses the future stream of dividends. Her payoff, therefore, is $S_{\theta}+e^{-\rho t}\left(B_{\theta}(v)-S_{\theta}\right)$, similar to $(7)$. That is, the model can be used to describe markets where buyers offer a fixed amount of money in exchange for an equity share of varying size, or markets where buyers obtain a fixed asset/equity stake of unknown quality for varying prices (and hybrid situations as well).

Definition 2. Equilibrium is in steady state if $V^{i}$ is a stationary process for all $i \in \mathcal{I}$ and $\left(m_{t}^{g}, m_{t}^{b}\right)$ are constant over time.

The next section characterizes the steady state equilibria of the model.

\section{$3 \quad$ Steady State Equilibria}

\subsection{Preliminary Analysis}

Before fully characterizing the steady state, I describe properties of any equilibrium which greatly simplify the analysis. I begin by showing in Lemma 1 that in any equilibrium entrepreneurs are using threshold strategies.

\section{Lemma 1. (Threshold Strategies)}

There exist two deterministic functions $r_{t}^{g}$ and $r_{t}^{b}$ such that any entrepreneur with a $\theta$ quality 
project in the market at time $t$ rejects all offers $v<r_{t}^{\theta}$ and raises funds with probability 1 if offered a valuation $v>r_{t}^{\theta}$.

The intuition behind Lemma 1 strongly relies on the private offers assumption. Since investors do not observe previous offers, the continuation value for any entrepreneur does not depend on the current valuation itself or on her acceptance decision (even when considering an off-equilibrium deviation). Thus, any valuation strictly higher than the continuation value triggers acceptance and any valuation strictly lower than continuation value will be rejected. Furthermore, I demonstrate in Lemma 2 that these two thresholds can be ranked.

\section{Lemma 2. (Skimming Property)}

At any time $t$,

$$
r_{t}^{g}>r_{t}^{b}
$$

Lemma 2 implies that if some price is attractive for the entrepreneur with a good project, then the price will be accepted with probability 1 by the entrepreneur with a bad project. Without asymmetric information, the good project is more valuable than the bad one. Hence, $S_{\theta}$ serves as an option value of delaying investment until information revelation. This option is less valuable when the project is bad, which creates incentives for the entrepreneur to accept lower valuations. ${ }^{10}$

Lemmas 1 and 2 uniquely define an entrepreneur's best response to any valuation $v$ which is not equal to $r_{t}^{g}$ or $r_{t}^{b}$. When the valuation is equal to either of the respective thresholds, an entrepreneur with a corresponding project is indifferent; nevertheless, in any equilibrium the action of an entrepreneur with a good project is uniquely pinned down by Lemma 3 .

\section{Lemma 3. (No mixing at $r_{t}^{g}$ )}

An entrepreneur with a good quality project never plays a mixed strategy. In particular, she accepts all offers with valuations $v \geq r_{t}^{g}$.

If an entrepreneur with a good project were mixing at some offer $v=r_{t}^{g}$, then the average quality of projects funded at this price would be below the current average quality of projects in the market. Recall that, on the one hand, $r_{t}^{g}$ equals the expected continuation value of the entrepreneur with a good project and, on the other hand, investors break even at $v$. These two facts together imply that the first part of the market clearing condition is violated.

\footnotetext{
${ }^{10}$ Similarly to Kremer and Skrzypacz (2007), in my model single crossing arises not from costs but from benefits of delay.
} 


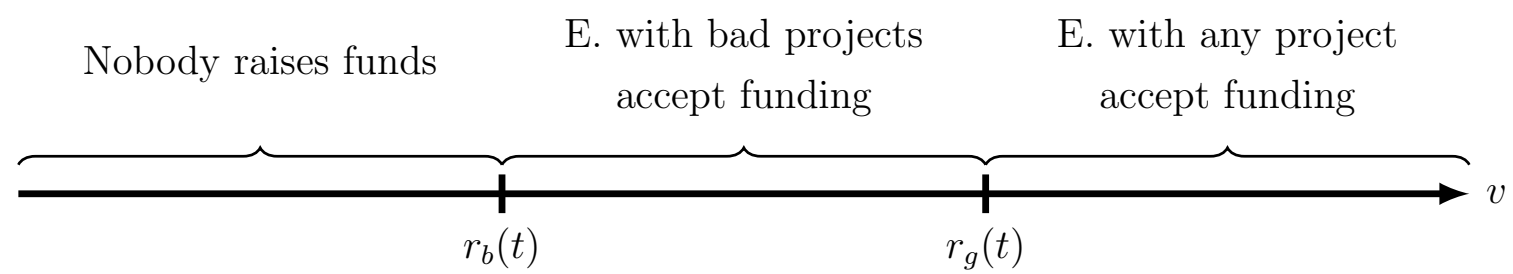

Figure 2: Fund-raising decisions of entrepreneurs given a valuation $v$

The optimal behavior of entrepreneurs together with a break-even constraint for investors puts strong discipline on the equilibrium set of offered valuations. In particular, any valuation $v>r_{t}^{g}$ or $v \in\left(r_{t}^{b}, r_{t}^{g}\right)$ would lose money for investors and therefore will not occur in equilibrium. Price offers that can occur in equilibrium are classified in Corollary 1.

Corollary 1. In any equilibrium, any valuation $v \in \mathcal{V}_{t}$ offered at time $t$ is either

Pooling Offer $v=\frac{\delta_{X}}{\delta_{X}+r}\left(\pi_{t} X_{g}+\left(1-\pi_{t}\right) X_{b}\right)$, or

Separating Offer $v=\frac{\delta_{X}}{\delta_{X}+r} X_{b}$, or

Losing Offer $v<\frac{\delta_{X}}{\delta_{X}+r} X_{b}$.

For any equilibrium in which losing offers are made, one can construct an equilibrium by replacing all losing offers with a separating offer and adjusting the probability of acceptance of the separating offer by the entrepreneurs with bad projects. Without loss of generality, I focus on equilibria in which only pooling and separating offers are made.

\subsection{Equilibrium Construction}

I construct a steady state equilibrium in two steps. First, I exogenously fix the entry rate $G(c)$ of entrepreneurs with bad projects to the market and solve for a steady state equilibrium. Then, I endogenize the (constant) $c_{t}$ by tying the entry cut-off with the equilibrium continuation value using condition (10).

In the steady state equilibrium incentives of an entrepreneur with good quality project to accept a pooling offer are driven by the following comparison:

$$
\frac{\rho}{\delta+\rho}\left[\frac{\delta_{X}}{\delta_{X}+r} X_{g}-I\right] \text { vs. } \frac{\left(1-\pi_{t}\right) I\left(X_{g}-X_{b}\right)}{\pi X_{g}+(1-\pi) X_{b}} .
$$


The left-hand side of expression (14) represents the benefit due to early investment (recall that the signal about the project quality is revealed with intensity $\delta$ ), while the right-hand side stands for the underpricing costs. Underpricing costs are lower when investors' belief $\pi_{t}$ is higher (underpricing completely disappears when $\pi_{t}=1$ ), when funding need $I$ is lower, and when $X_{g}-X_{b}$ is lower.

Whenever the right-hand side of expression (14) is higher than the left-hand side, entrepreneurs with a good project would rather wait for information revelation than raise funds at the current pooling valuation. Similar to Akerlof (1970), the market for lemons develops. The dynamic continuation value of entrepreneurs plays a role of the seller's cost from Akerlof's model and precludes trade at the average price.

Denote by $\hat{\pi}$ the value of $\pi_{t}$ that equates the left- and right-hand sides of expression (14). When the quality of newly arrived projects $1 /\left(1+G\left(c_{t}\right)\right)$ is above $\hat{\pi}$, then immediate acceptance of a pooling offer for the entrepreneurs with good projects is incentive compatible.

However, when $1 /\left(1+G\left(c_{t}\right)\right)$ is below $\hat{\pi}$, immediate pooling is not the best response (i.e., the lemons condition is binding). It cannot also be true that in equilibrium entrepreneurs with good projects never raise funds prior to information revelation, for if it were the case, then all entrepreneurs with bad projects would raise funding at the moment of entry. In an arbitrarily small amount of time, the investors' belief about remaining types in the market would reach $\pi_{t}=1$. The unique continuation equilibrium would then have immediate trade at the pooling offer, which is strictly higher than the low valuations just a few moments earlier. It would make it suboptimal for the entrepreneurs with bad projects to raise funds immediately upon market entry.

The only way entrepreneurs with bad and good projects would be able to raise funds in equilibrium, when $1 /\left(1+G\left(c_{t}\right)\right)$ is below $\hat{\pi}$, is through delayed trade at the pooling valuation. Higher expected time to raise funds at pooling valuation incentivizes some entrepreneurs with bad projects to accept an always standing low separating offer. This scenario improves average quality of projects in the market and allows investors to break even when offering a high pooling valuation.

Denote by $\alpha=\frac{1}{1+G(c)}$ the fraction of entrepreneurs with good projects entering the market. Proposition 1 characterizes the steady state equilibrium for an exogenously fixed $\alpha$.

\section{Proposition 1.}

1. If $\alpha>\hat{\pi}$, then there exists an essentially ${ }^{11}$ unique steady state equilibrium. Along the

\footnotetext{
${ }^{11}$ The equilibrium is unique up to (i) implementation of mixed strategy by a continuum of entrepreneurs and (ii) measure zero of entrepreneurs following an arbitrary strategy.
} 
equilibrium path, all projects are funded at pooling $(\alpha)$ valuation upon entry.

2. If $\alpha<\hat{\pi}$, then there exists an essentially unique steady state equilibrium. Along the equilibrium path:

(a) Good projects raise funds at pooling ( $\hat{\pi})$ valuation;

(b) Bad projects raise funds at separating and pooling $(\hat{\pi})$ valuations;

(c) Supply is rationed at the pooling $(\hat{\pi})$ valuation.

3. If $\alpha=\hat{\pi}$, there exists a continuum of steady state equilibria. Along the equilibrium path, funds are raised at pooling $(\hat{\pi})$ valuations and supply is rationed.

When $\alpha<\hat{\pi}$, funds are raised at pooling and separating valuations at the same time (see Figure 3). Through mixing on the investor side of the market at each time $t$, a fraction of entrepreneurs is offered a pooling valuation that both types accept. However, a vast majority of the investors offer to invest only at low (separating) valuation. Such an offer is rejected by entrepreneurs with good projects. Entrepreneurs with bad projects randomize between acceptance and rejection, with only a flow of bad types accepting, so that investor beliefs change continuously.

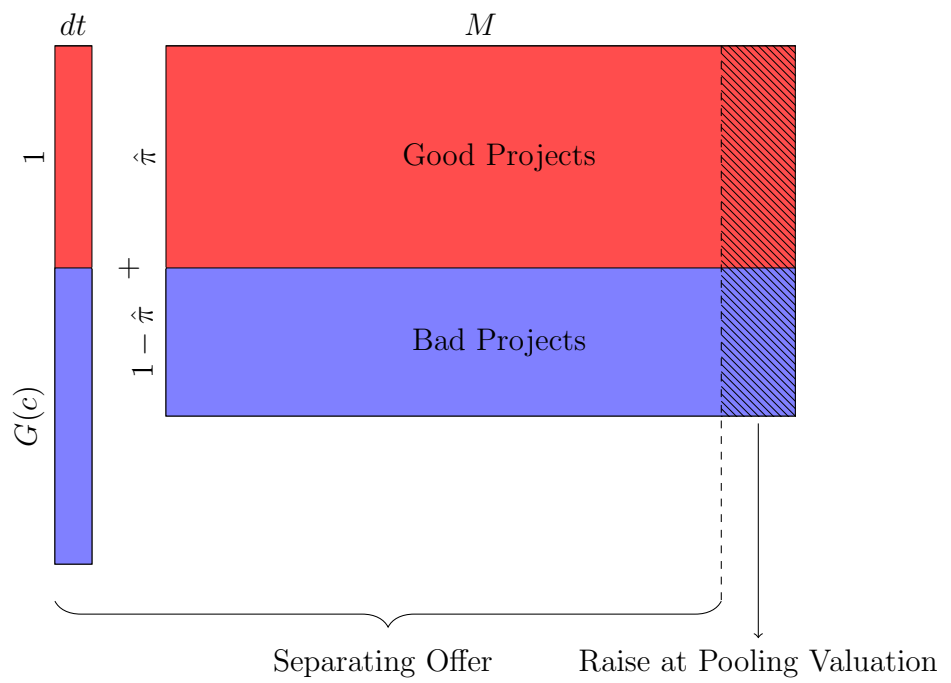

Figure 3: Partial Pooling in the Steady State

With a slight abuse of notation, let $B_{\theta}(\pi)$ denote the expected value of accepting a pooling offer for the entrepreneur with a $\theta$ quality project when investors' belief is $\pi$. Then 
equilibrium payoff $W^{b}$ to the same entrepreneur is:

$$
W^{b}(\alpha)= \begin{cases}B_{b}(\alpha), & \text { if } \alpha=\frac{1}{1+G(c)}>\hat{\pi} \\ B_{b}(0), & \text { if } \alpha=\frac{1}{1+G(c)}<\hat{\pi} \\ {\left[B_{b}(0), B_{b}(\hat{\pi})\right],} & \text { if } \alpha=\frac{1}{1+G(c)}=\hat{\pi}\end{cases}
$$

At $t^{i}$, each entrepreneur with a bad project weighs the cost of entry $c^{i}$ and the expected equilibrium payoff $W^{b}$. Those with costs below $W^{b}$ choose to enter; hence, the entry rate of bad projects is $G\left(W^{b}\right)$. In order to solve for the steady state equilibrium with endogenous entry, the actual proportion of high-quality projects needs to coincide with the one expected by investors. Proposition 2 establishes existence and uniqueness of the equilibrium with endogenous entry.

Proposition 2. There exits an essentially unique steady state equilibrium. Proportion $\alpha^{*}$ of good projects entering the market every period is the unique root of:

$$
\frac{1}{1+G\left(W^{b}\left(\alpha^{*}\right)\right)}=\alpha^{*}
$$

Given $\alpha^{*}$, the equilibrium outcome is characterized by Proposition 1.

When equilibrium quality of entry $\alpha^{*}$ is below $\hat{\pi}$ (i.e., the lemons condition is binding), then equilibrium in the funding market is inefficient. Since the private $\operatorname{cost} c^{i}$ is sunk, Assumption 1 implies that conditional on entry all the projects should be financed immediately in the first best. However, in equilibrium it takes time to raise funds and efficiency is lost due to discounting.

However, illiquidity in the fund-raising market has a second, welfare improving side. Delayed funding at high prices serves as an imperfect screening mechanism that allows investors to separate entrepreneurs with good projects from (some) entrepreneurs with bad projects. Partial sorting of the projects implies that equilibrium payoff to entrepreneurs with bad projects equals the true value of their idea, thus, their market entry decisions are efficient. ${ }^{12}$ On the other hand, when $\alpha^{*}$ is above $\hat{\pi}$ and the equilibrium features immediate pooling, the entrepreneurs with bad projects get a payoff higher than the true value of their project, hence, the entry is inefficiently high.

\footnotetext{
${ }^{12}$ Since I have assumed that market entry of entrepreneurs with good projects is inelastic, in steady state the entry is efficient. However, entrepreneurs with good projects do not receive the true value for their projects. If their rate of entry depended on the expected return, it would be inefficient.
} 
Figure 4: Steady State Equilibrium With Endogenous Entry

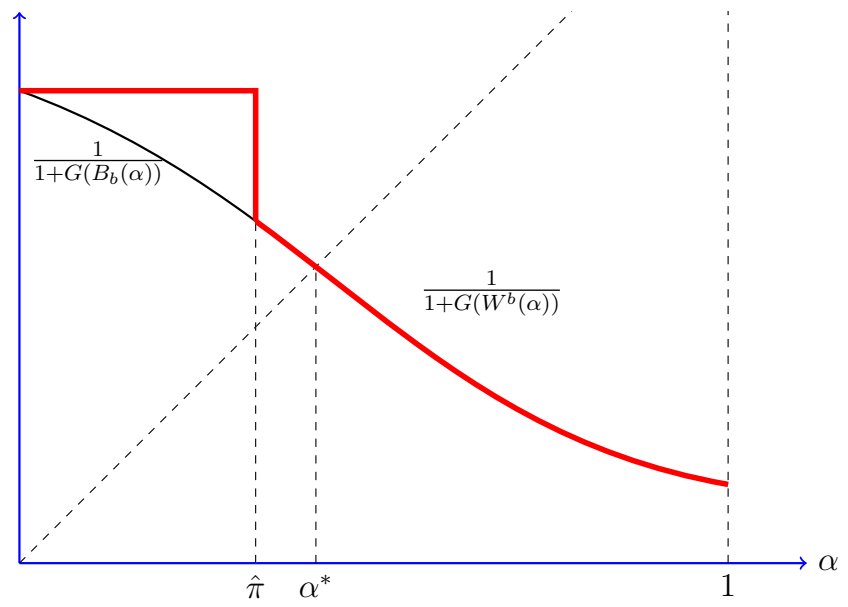

(a) Equilibrium with $\hat{\pi}<\alpha^{*}$

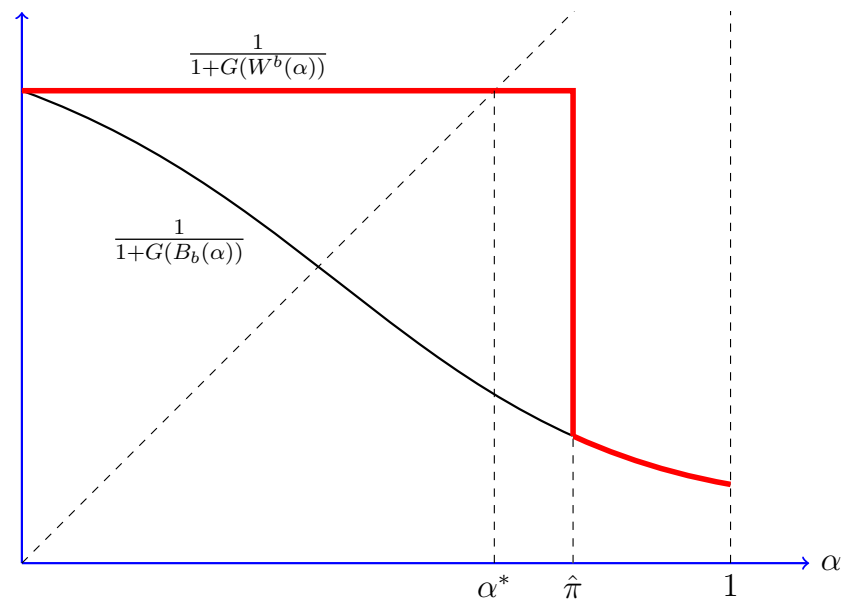

(b) Equilibrium with $\hat{\pi}>\alpha^{*}$

A combination of observations discussed above leads to the Proposition 3.

Proposition 3. The steady state equilibrium is always inefficient: if $\alpha^{*} \leq \hat{\pi}$, then positive gains from trade are realized with a delay; if $\alpha^{*}>\hat{\pi}$, there is an excessive entry of bad projects into the market.

\subsection{Varying the Discount Rate}

In this section I explore how the nature of the steady state equilibrium depends on the discount rates of investors. Proposition 4 describes the dependence of the fraction $\alpha^{*}$ of good projects entering the market on the discount rate of investors, $r$.

Proposition 4. The equilibrium fraction $\alpha^{*}$ of good projects entering the market in every period increases with the discount rate of investors, $r$.

An increase in the discount rate of investors increases the costs of the early financing of good projects in two ways. First, it leads to a decrease in the differential benefits of early investment, because the NPV of the projects becomes smaller. Second, it also leads to an increase in adverse selection costs, because investors demand a higher equity share 
regardless of the project's quality. Both of these factors increase $\hat{\pi}$. In addition, an increase in $r$ decreases the payoff to the entrepreneurs with bad projects conditional on pooling, $B_{b}(\pi)$. A lower payoff conditional on pooling and a decrease in the willingness of owners of good projects to pool reduces incentives of entrepreneurs with bad projects to enter the market.

Both, equilibrium quality of entry $\alpha^{*}$ and the lemons condition threshold $\hat{\pi}$ move in the same direction when investors' discount rate $r$ changes. In order to rank them, I propose Assumption 3.

Assumption 3. Let the parameters of the model satisfy:

$$
\begin{aligned}
& \text { (i) } \frac{\rho}{\delta+\rho}\left(\frac{\delta_{X}}{\delta_{X}+\rho} X_{g}-I\right)<I\left(\frac{X_{g}}{X_{b}}-1\right)<\frac{\rho}{\delta+\rho}\left(X_{g}-I\right) \text {, } \\
& \text { (ii) } G\left(\frac{\delta_{X}}{\delta_{X}+\rho} X_{b}-I\right)>\frac{1}{\hat{\pi}_{r=\rho}}-1,
\end{aligned}
$$

where $\hat{\pi}_{r=\rho}$ is a solution of (14) with $r=\rho$.

Part (i) of Assumption 3 makes sure that there is enough variation in the gains from trade between investors and entrepreneurs relative to the adverse selection discount. Part (ii) of Assumption 3 rules out the case when the distribution of private costs of entry is so steep that not enough bad projects enter the market to make the lemons condition binding. Proposition 5 characterizes the structure of the steady state equilibrium for sufficiently high and low discount rate, $r$.

Proposition 5. If parameters satisfy Assumption 3, then there exist two thresholds $0<\underline{r}<$ $\bar{r}<\rho$ such that

(i) for all $r<\underline{r}$ steady state equilibrium features $\alpha^{*}>\hat{\pi}$,

(ii) for all $r>\bar{r}$ steady state equilibrium features $\alpha^{*}<\hat{\pi}$.

\section{Transition Dynamics}

I have shown that a lower discount factor of investors increases the incentives for entrepreneurs with lower quality projects to enter the market. This activity reduces the average quality of projects in the market. In this section, I use a dynamic model to explore how discount rate variation impacts the volume of funded projects, as well as the quality of projects receiving funding. 
State Process. The dynamics of the discount rate are driven by a publicly observable Markov switching state process, $Y=\left(Y_{t}\right)_{t \geq 0}$, which takes two values $Y_{t} \in\{0,1\}$. Denote by $\lambda^{1}$ the arrival intensity of state 1 conditional on $Y_{t}=0$, and by $\lambda^{0}$ the arrival intensity of state 0 conditional on $Y_{t}=1$. Let the interest rate of investors $r(y)$ satisfy the following inequality:

$$
0<r(1)<\underline{r}<\bar{r}<r(0)<\rho .
$$

Inequality (17) implies that in the steady state equilibrium, the lemons condition is binding when $Y=0$ and not binding when $Y=1$. Intuitively, in state $Y_{t}=1$, investors' capital is in abundance, thus, it is cheaper to finance. In $Y_{t}=0$, capital is scarce and funding is more costly.

Histories and Strategies. The definitions of strategies and equilibrium from Section 2 need to be augmented to allow for state contingency. Define the public history as $\mathcal{H}=\left(\mathcal{H}_{t}\right)_{t \geq 0}$, where $\mathcal{H}_{t}$ is generated by $\left\{Y_{u} ; u \leq t\right\}$.

The private history of entrepreneur $i$ now includes both the public history as well as all previously received price offers, i.e., $\mathcal{H}_{t}^{i}=\sigma\left\{H_{t} ; V_{s}^{i}, s \leq t\right\}$. Similarly to Section 2, entrepreneur's strategy $F^{i}$ is a non-decreasing cádlág stochastic process $F^{i}=\left(F_{t}^{i}\right)_{t \geq t^{i}}$ adapted to private history $\left(\mathcal{H}_{t}^{i}\right)_{t \geq t^{i}}$ such that $0 \leq F_{t}^{i} \leq 1$ for all $t \geq t^{i}$.

The price processes $V^{i}$ are now allowed to depend on the public history, since the state process is observed by all investors. Private offers and anonymity conditions are easily adapted to incorporate state dependency by replacing independence with conditional independence. In particular, a collection of price offers $\left(V^{i}\right)_{i \in \mathcal{I}}$ satisfies the private offers restriction if $\sigma\left\{V_{s}^{i} ; s<t\right\}$ is independent from $\sigma\left\{V_{s}^{i} ; s \geq t\right\}$ conditional on $\mathcal{H}_{t}$ for all $i \in \mathcal{I}$ and $t \geq t^{i}$; it satisfies the anonymity restriction if $\left\{V^{i}\right\}_{i \in \mathcal{I}}$ at i.i.d. conditional on $\mathcal{H}$.

Payoffs. Similarly to Section 2, define an investor's valuation of a $\theta$ quality project conditional on state $Y_{t}=y$ as:

$$
V_{\theta}(y)=D_{X}(y) X_{\theta}
$$

where $D_{X}(y)$ is the expected discounted time until the project pay-out conditional on the current state being $y \cdot{ }^{13}$ If a type $\theta$ entrepreneur raises funds in state $Y_{t}=y$ at valuation $v$, then her payoff is:

$$
B_{\theta}(\pi ; y)=\frac{\delta_{X}}{\delta_{X}+\rho} X_{\theta}\left(1-\frac{I}{v}\right) .
$$

Let $S_{\theta}(y)$ be the expected payoff to a type $\theta$ entrepreneur from obtaining funding upon

\footnotetext{
${ }^{13}$ The values $D_{X}(y)$ uniquely solve a linear system $\left(r(y)+\delta_{X}+\lambda^{1-y}\right) D_{X}(y)=\delta_{X}+\lambda^{1-y} D_{X}(1-y)$ for $y \in\{0,1\}$.
} 
information revelation. $S_{\theta}(y)$ can be written as:

$$
S_{\theta}(y)=\frac{\delta}{\delta+\rho}\left[p(1, y) B_{\theta}\left(V_{\theta} ; 1\right)+(1-p(1, y)) B_{\theta}\left(V_{\theta} ; 0\right)\right]
$$

where $p\left(y^{\prime}, y\right)$ is the probability of state being $y^{\prime}$ at the moment of information revelation, conditional on the current state being $y \cdot{ }^{14}$ In equilibrium, every entrepreneur $i$ solves an optimal stopping problem similar to the one in Section 2:

$$
\sup _{F^{i}} \mathrm{E}\left[S_{\theta^{i}}\left(Y_{t^{i}}\right)+\int_{t^{i}}^{\infty} e^{-(\rho+\delta)\left(\tau-t^{i}\right)}\left(B_{\theta}\left(V_{\tau}^{i}, Y_{\tau}\right)-S_{\theta^{i}}\left(Y_{\tau}\right)\right) d F_{\tau}^{i} \mid \mathcal{H}_{t}^{i}\right]
$$

Definition 3 concerns an equilibrium of the model with stochastic discount rate.

Definition 3. An equilibrium with stochastic discount rate is quadruple $\left(F, V, m^{g}, m^{b}\right)$ with induced continuation values $\left(W_{t}^{g}, W_{t}^{b}\right)$ that satisfy:

1. Seller Optimality: Given $V^{i}, F^{i}$ solves entrepreneur's problem (21) for all $i$ and $t \geq t^{i}$. The entry cut-off is given by:

$$
c_{t}=W_{t}^{b}
$$

\section{Buyer Optimality:}

(a) Zero Profit: For any valuation $v \in \mathcal{V}_{t}$ offered at time $t$ either there does not exist $i$ such that $\tau^{i}=t$ and $V_{t}^{i}=v$, or

$$
v=D_{X}\left(Y_{t}\right) \cdot E\left(X_{\theta^{i}} \mid V_{t}^{i}=v, \tau^{i}=t\right)
$$

(b) Market Clearing:

$$
W_{t}^{g} \geq B_{g}\left(D_{X}\left(Y_{t}\right) \cdot\left(\pi_{t} X_{g}+\left(1-\pi_{t}\right) X_{b}\right)\right) \quad \text { and } \quad W_{t}^{b} \geq B_{b}\left(D_{X}\left(Y_{t}\right) \cdot X_{b}\right)
$$

3. Belief Consistency: Investors' belief about the proportion of good quality projects in the market is consistent with $m^{g}$ and $m^{b}$ induced by entry of new projects (characterized by the entry cut-off $c_{t}$ ) and fund-raising decisions induced by the entrepreneurs' strategy $F$ and offered prices $V$.

\footnotetext{
${ }^{14}$ Conditional probabilities $p\left(y^{\prime}, y\right)$ are the unique solution of the linear system $\left(r(y)+\delta+\lambda^{1-y}\right) p\left(y^{\prime}, y\right)=$ $\delta \mathbb{1}\left(y^{\prime}=y\right)+\lambda^{1-y} p\left(y^{\prime}, 1-y\right)$ for $y^{\prime}, y \in\{0,1\}$.
} 
Proposition 6 shows the existence of a dynamic equilibrium when state transitions do not happen very often.

Proposition 6. For sufficiently small $\lambda^{1}$ and $\lambda^{0}$ there exists an equilibrium with stochastic discount rate.

I now characterize the most salient properties of the equilibrium.

\subsection{Wave of Deals}

Proposition 7 concerns the equilibrium deal volume. I show that a decrease in investors' discount rate brings in an abundance of fund-raising activity, i.e., a wave of deals.

Proposition 7. In the equilibrium of Proposition 6 when the discount rate of investors decreases from $r(0)$ to $r(1)$, a wave of deals follows. The average quality of the projects funded at the moment of transition is strictly higher than the average quality of projects funded at any other time.

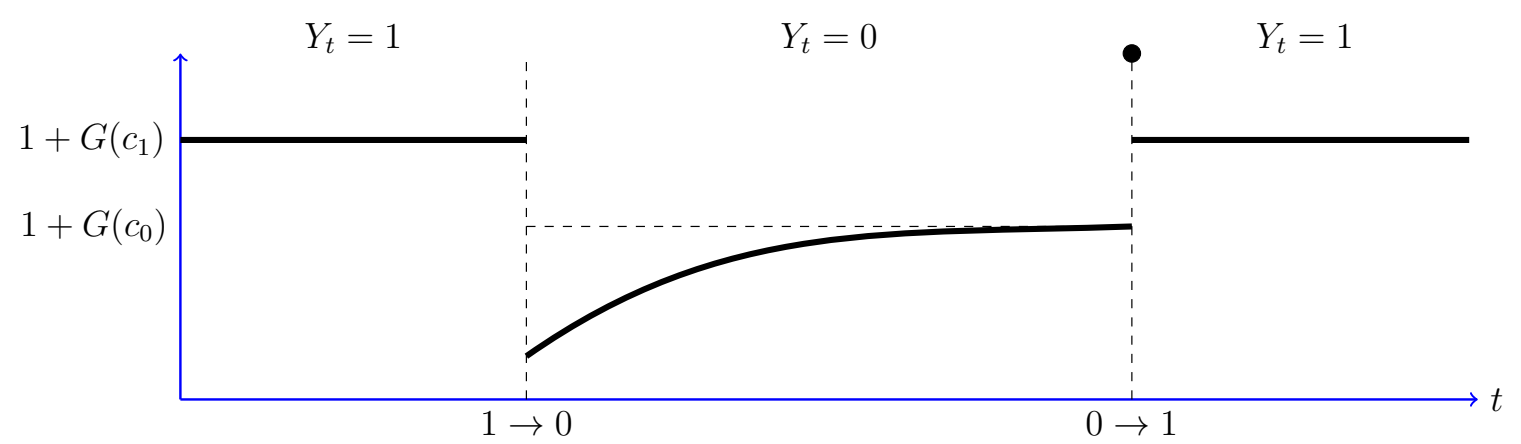

Figure 5: Volume of Deals at Time $t$

When the discount rate decreases, incentives to delay fund-raising disappear for two reasons. First, conditional on the average quality of projects in the market, valuations are as high as they are ever going to be. Second, more importantly, higher valuations attract lower quality projects to the market, thus, in expectation the prices will be decreasing. Strict preferences of entrepreneurs with good projects for immediate trade together with the market clearing condition require for pooling valuation to be offered and accepted with probability 1. Accumulation of unfunded projects during periods with high discount rates together with the previous observation imply that there is going to be an atom of funding (see Figure 5) when the discount rate falls to $r(1)$. 
The quality of the projects funded at the time of transition to $Y_{t}=1$ is equal to the average quality of unfunded projects a second earlier. Due to illiquidity in state 0, the average quality of unfunded projects is strictly higher than the quality of projects entering the market, which, in turn, is higher than the average quality of those being funded. Right after the transition, the average quality significantly drops, since high valuations and ease of securing financing attracts lower quality projects to the market.

The economic mechanism underlying the wave of deals in my model is novel and very different from those previously proposed in the literature. In particular, it leads to different observable dynamics in the quality of funded projects in hot markets. For example, Pástor and Veronesi (2005) and Bustamante (2012) use the real option framework to explain the clustering of IPO deals over time. The optimal exercise threshold of a real option is a decreasing function of project's quality, thus, an improvement in market conditions triggers owners of lower quality projects to exercise their options. As a result, Pástor and Veronesi (2005) and Bustamante (2012) predict that the quality of funded projects is the highest in cold markets and always lower in hot markets. A similar pattern arises from the static adverse selection model of Yung, Çolak and Wei (2008). In contrast, the quantity of funded projects in my model is the highest early in the wave, since the quantity adjustment comes from the top part of the quality distribution. It is the entrepreneurs with high-quality projects who partially withdraw from the market in bad times and rush back, generating a wave of deals, when market conditions improve.

\subsection{Average Quality of Funded Projects}

This section describes the dynamics of the average quality of funded projects. Proposition 8 compares the average quality of funded projects in states 0 and 1.

Proposition 8. In the equilibrium of Proposition 6, the average quality of funded projects in state $Y_{t}=0$ is higher than in state $Y_{t}=1$ if the corresponding state lasts sufficiently long.

Figure 6 shows the dynamics of the average quality of funded projects over time. In state $Y_{t}=1$ with the low discount rate, funding is raised immediately. Therefore, the average quality of the projects conditional on receiving financing is fully determined by the quality of the projects entering the market. High prices and the ease of obtaining funding attracts a pool of projects of low average quality.

In state $Y_{t}=0$, however, projects are financed at both separating and pooling valuations. Conditional on raising funding at the separating valuation, the quality of the project 


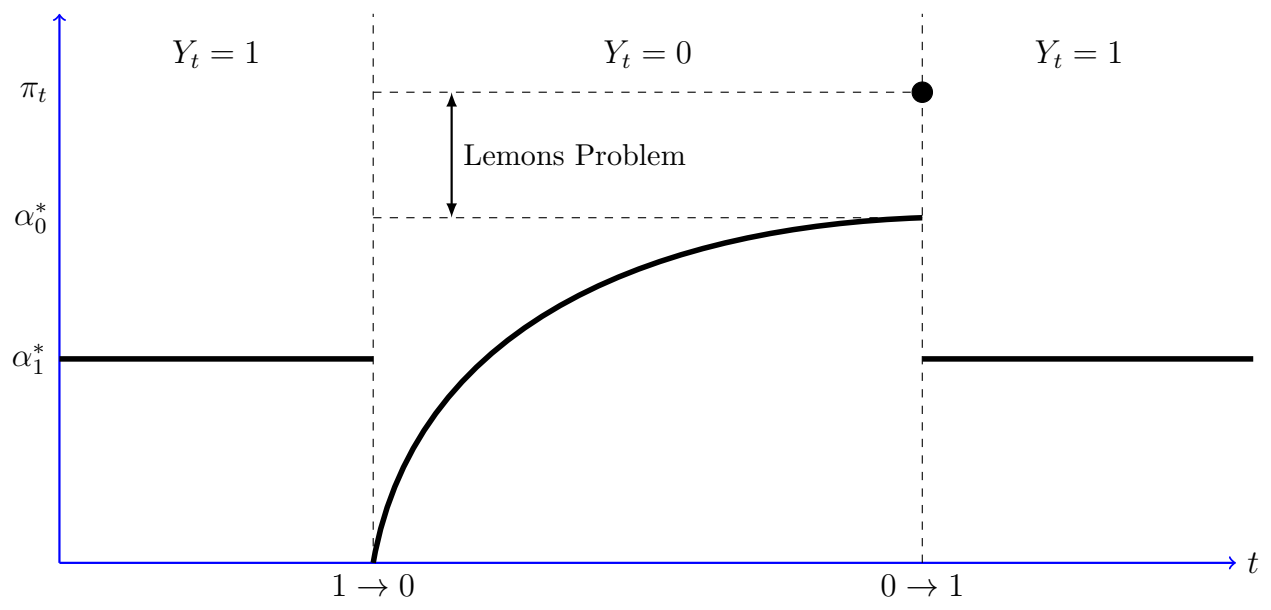

Figure 6: Fraction of Good Projects Funded at Time $t$

is always low while those funded at the pooling valuation are on average of very high quality. The average quality conditional on getting funded, thus, is a weighted average of a low (separating) and high (pooling) project quality. The acceptance rate of the separating valuation is constant over time. At the same time, the acceptance rate of pooling valuation increases over time due to an accumulation of projects in the market. Thus, the volumeweighted average quality of funded projects increases over time. It eventually approaches the steady state quality, which is equal to the quality of the projects entering the market. In equilibrium, entrepreneurs with bad projects are indifferent between accepting a separating price and waiting to get a pooling price, thus, $W_{t}^{b}=B_{b}\left(D_{X}(0) X_{b}\right)$ when $Y_{t}=0$. The high discount rate and lack of overpricing attracts fewer entrepreneurs with bad projects to the market, resulting in $\alpha_{0}^{*}>\alpha_{1}^{*}$.

\subsection{Liquidity and Entry}

This section explores welfare properties of the equilibrium with stochastic discount rate. Proposition 9 discusses two different forces, illiquidity and excessive entry, that impede efficiency.

Proposition 9. The equilibrium of Proposition 6 is never efficient: when $Y_{t}=0$, funds on average are raised with a positive delay, and when $Y_{t}=1$, there is an excessive entry of entrepreneurs with lower quality projects.

When the discount rate is low $\left(Y_{t}=1\right)$, every entrepreneur entering the market immediately secures funds at pooling valuation. This is not, however, the case in state $Y_{t}=0$. 
When the discount rate is high, immediate funding can be secured only at a separating valuation, which is unacceptable for entrepreneurs with good projects, so only a fraction of lower quality projects is funded at low valuations. The vast majority of the market is attempting to secure funding at the pooling valuation, which leads to a delay. Since pooling valuation is offered with intensity $\lambda_{p}$, the funding rate at this valuation is $\lambda_{p}\left(m_{t}^{g}+m_{t}^{b}\right)$. At the time of arrival of $Y_{t}=0$, both $m_{t}^{g}$ and $m_{t}^{b}$ are zero, and the inflow rate of new entrepreneurs is positive. Hence, inventory starts accumulating (see Figure 7).

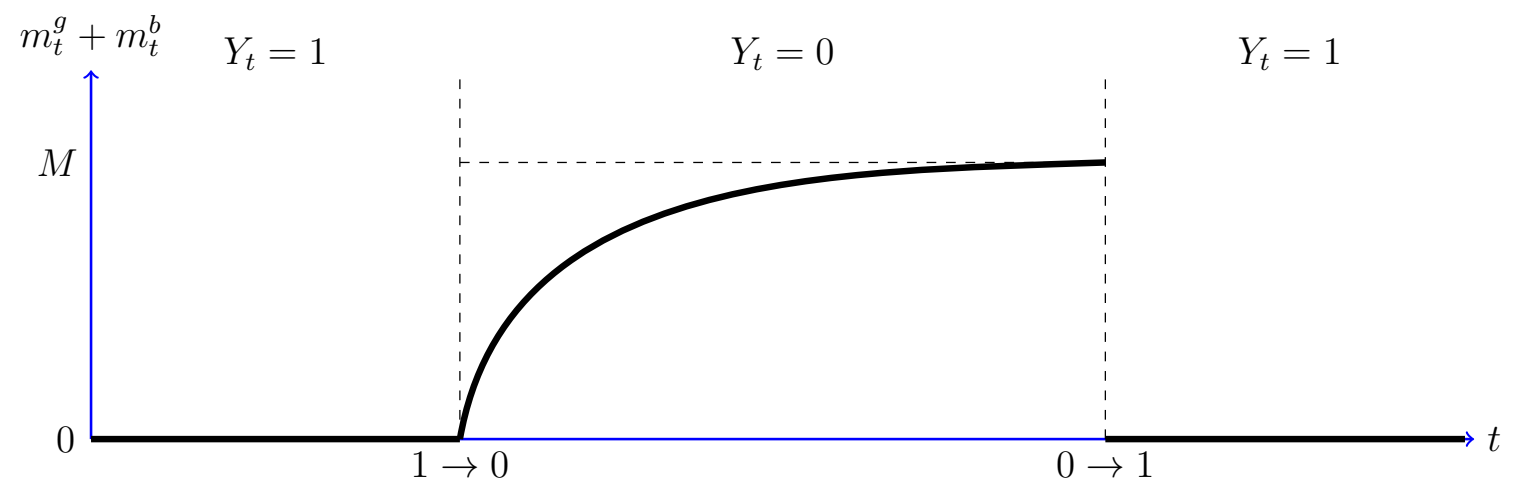

Figure 7: Volume of Unfunded Projects at Time $t$

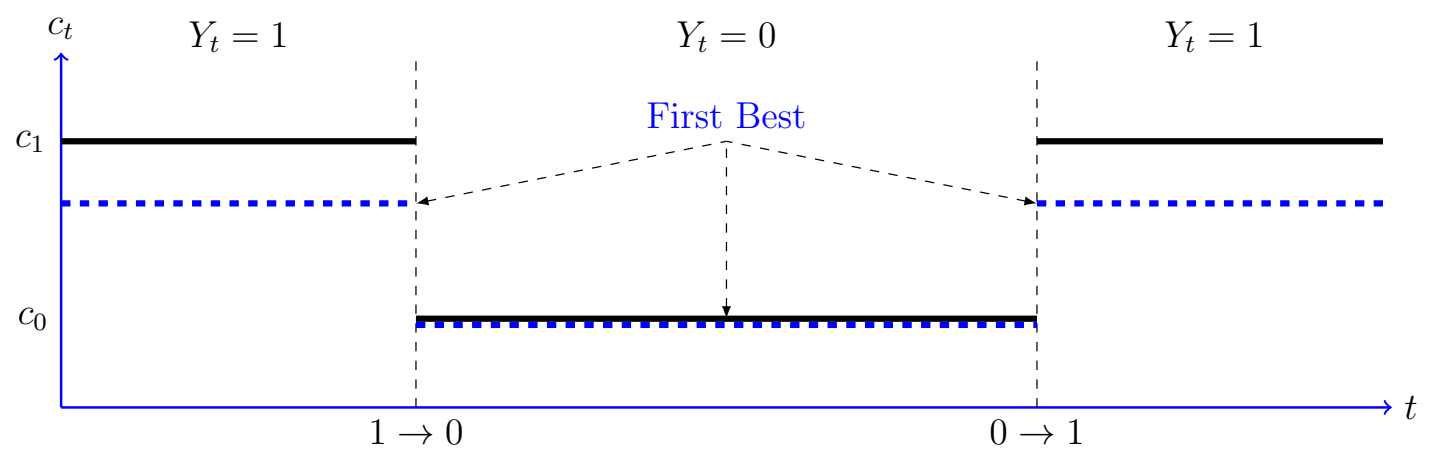

Figure 8: Entry Threshold $c_{t}$

On the other hand, illiquidity in state $Y_{t}=0$ allows for the partial screening of projects. The equilibrium payoff of the entrepreneur entering the market, when discount rate is high, is exactly $B_{b}\left(D_{X}(0) X_{b} ; 0\right)$. It implies that the NPV of the marginal project entering the market, taking into account the private cost of entry $c^{i}$, is zero. Thus, equilibrium entry threshold $c_{t}$ is at the first best level, as shown in Figure 8. When the state is $Y_{t}=1$, equilibrium features immediate pooling and equilibrium continuation value of an entrepreneur with a bad project 
entering the market is $B_{b}\left(D_{X}(1)\left(\alpha_{1}^{*} X_{g}+\left(1-\alpha_{1}^{*}\right) X_{b}\right) ; 1\right)$. In addition to a low discount rate, owners of lower quality projects enjoy the benefits of overpriced equity. Such an implicit subsidy distorts incentives to enter the market. Indeed, the NPV of the marginal project brought to the market in the state with low discount rate is:

$$
B_{b}\left(D_{X}(1) X_{b} ; 1\right)-c_{t}=B_{b}\left(D_{X}(1) X_{b} ; 1\right)-B_{b}\left(D_{X}(1)\left(\alpha_{1}^{*} X_{g}+\left(1-\alpha_{1}^{*}\right) X_{b}\right) ; 1\right)<0 .
$$

Hence, when $Y_{t}=1$, the equilibrium is inefficient due to an excessive entry of entrepreneurs with lower quality projects.

\section{$5 \quad$ Empirical Implications}

The results based on the equilibrium of the model naturally lead to several empirical implications.

Volume of Deals. My model can be used to demonstrate that the volume of deals and market prices are positively correlated with market conditions. Lower gains from trade caused by, for example, higher cost of investors' capital, cause not only the price adjustment but also a quantity adjustment, because owners of high-quality projects find it optimal to partially withdraw from the market. This prediction is broadly consistent with the findings across multiple markets in which adverse selection is an important concern. In the venture capital industry, fund inflows significantly affect the number of funded ventures. In addition, Gompers and Lerner (2000) document that fund flows predict valuations of startups. Ax-

elson, Jenkinson, Strömberg and Weisbach (2009) show that cost of debt drives the volume and valuation levels in private equity buyouts. Similarly, in IPO and merger and acquisition markets, Pagano, Panetta and Zingales (1998) and Ball, Chiu and Smith (2011) find that the volume of deals is explained by market conditions. Secondary equity issuances seem to exhibit a similar pattern: Baker and Wurgler (2002) argue that the timing of market conditions is an important determinant of firms' capital structure, while Choe, Masulis and Nanda (1993) show that firms increase equity offerings (relative to debt offerings) during periods of economic expansion, consistent with my predictions.

Additionally, my model can be used to generate a wave of deals, which is a definitive feature of IPO (Ritter and Welch (2002)) and private equity buyout (Kaplan and Stein (1993)) markets. 
Quality of Funded Projects. In my model, the quality of funded projects is nonmonotonic with respect to market conditions (and volume of deals). The quality is low when the discount rates have been low for a prolonged period of time. Conversely, it is higher when discount rates are high, and it is the highest early in the fund-raising wave. This implies that the empirically measured quality of funded projects might strongly depend on the definition of hot/cold markets. Nevertheless, this prediction has found support across several markets. In the context of IPOs, Ritter and Welch (2002) write that "it is conventional wisdom among both academics and practitioners that the quality of firms going public deteriorates as a period of high issuing volume progresses." This is consistent with my findings and is confirmed by Chang, Kim and Shim (2013), who show that firms issuing earlier in hot markets are of higher quality than firms issuing later. Similarly, Kaplan and Stein (1993) document that transactions completed in late 1980's (following a long period of cheap access to debt) were of poorer quality: among the largest buyouts roughly every third resulted in some form of financial distress with every fourth actually defaulting on debt and filing for Chapter 11. In the context of venture capital funding, Nanda and Rhodes-Kropf (2013) find that startups raising funds in hot markets are more likely to fail, but conditional on not failing are more successful. This could be driven by the time-varying quality of funded projects: in my model, early in the hot markets, the average quality is the highest, then it deteriorates over time.

Time on the Market. Lastly, my model can be used to demonstrate that fund-raising takes more time when market conditions are bad. Moreover, startups that delay raising funds receive a better price and signal that their projects are of higher quality on average. Empirically, this prediction is harder to test, because the time when entrepreneur or firm first enters the funding market might not be observable. Thus, one should be careful when testing this prediction. For younger firms, however, this naturally leads to implications about a firm's age at the time of receiving financing. For example, one could test whether the age of startups raising Series A (first round of VC funding) covaries over time with VC fund flows. Specifically, whether older startups raising Series A round when VC funding is scarce are of higher quality and are able to secure better terms. 


\section{Conclusion}

In this paper, I examine the effects of time-varying market conditions and endogenous entry on equilibrium dynamics of markets with adverse selection. In my leading application, the early stage financing of high-growth firms, the variation in market conditions is driven by the availability of VC and angel capital.

I analyze the dynamics of the quality of projects receiving financing, as well as deal volume and market efficiency. During good times, when the supply of VC capital is high, entrepreneurs raise funds without delay. At the same time, the average quality of funded projects is typically low. During bad times, when supply of $\mathrm{VC}$ capital is low and the discount rate of investors is correspondingly high, raising funds takes longer on average, but the average quality of funded projects is typically high.

Time variation in market conditions creates incentives for entrepreneurs with higher quality projects to signal their type when the discount rate is high. Signaling takes the form of delayed fund-raising, which leads to an accumulation of unfunded projects in the market. Consequently, an improvement in market conditions and deterioration of incentives to signal quality triggers a wave of fund-raising activity.

I also uncover a previously unnoticed positive side of illiquidity. Delay in bad times, although wasteful due to the lost time value of positive NPV projects, allows investors to partially screen entrepreneurs. Equilibrium payoff to entrepreneurs with low-quality projects reflects the true value of their ideas, providing efficient entry incentives.

My model can be used to generate several empirical predictions that are broadly consistent with findings in early stage financing, IPO, private equity buyout, and secondary offering markets. 


\section{Appendix}

\section{A Price Processes}

Fix the probability space $(\Omega, \mathcal{F}, P)$. Let the index set be $\mathcal{I}=(-\infty, 1] \times \mathbb{R}_{+}$. Index $i=(x, t)$ stands for a potential entrepreneur $i$ who comes up with an idea at time $t$. Let $\theta^{i}=g$ if the $x$ coordinate of a potential entrepreneur's index is positive and $\theta^{i}=b$ if it is negative. In addition for potential entrepreneurs with bad ideas put the private cost of entry $c^{i}=G^{-1}(-x)$. Define mes as an extension of the Lebesgue measure with a sigma algebra of measurable sets $\mathcal{F}_{\mathcal{I}}$ such that $\left(\mathcal{I} \times \Omega, \mathcal{F}_{\mathcal{I}} \otimes \mathcal{F}\right.$, mes $\left.\otimes P\right)$ is a rich Fubini extension of the usual product space.

Put $T=\mathbb{R}_{+}$to be the time indexing set. Let $V$ be a real-valued measurable function on $\left((\mathcal{I} \times \Omega) \times T,\left(\mathcal{F}_{\mathcal{I}} \otimes \mathcal{F}\right) \times \mathcal{B}_{T}\right)$ which is a regular version of itself. Existence of such $F$ with essentially pairwise i.i.d. processes $V^{i}$ for arbitrary distribution of $V^{i}$ is guaranteed by Sun (2006).

Below I will consider a particular class of processes $\left(V^{i}\right)_{i \in \mathcal{I}}$ satisfying Assumption 2 that will be sufficient to consider for this paper.

Definition 4. Let $\left\{\xi_{k}^{i}\right\}_{k=0}^{\infty}$ be a sequence of independent bounded discrete random variables with finite support distributed according to $\left(F_{\xi, k}\right)_{k=0}^{\infty}$ and $\left(t_{k}\right)_{k=0}^{\infty}$ be an unbounded increasing sequence of non-negative constants. For each entrepreneur $i$ define $\left(N_{j}^{i}\right)_{j=1}^{n}-$ a collection of independent (and independent from all the $\xi$ 's) time non-homogeneous Poisson processes with deterministic intensities $\left(\lambda_{N_{j}}(t)\right)_{j=1}^{n}$. Finally, let $\left(v_{j}(t)\right)_{j=0}^{n}$ be a set of deterministic functions of finite variation. Then define $V_{t}^{i}$ as

$$
V_{t}^{i}= \begin{cases}\xi_{k}^{i}, & \text { if } t=t_{k} \\ \sum_{j=1}^{n} v_{k}(t) d N_{j}^{i}(t) \prod_{l \neq j}\left(1-d N_{l}^{i}(t)\right)+\prod_{j=1}^{n}\left(1-d N_{j}^{i}(t)\right) v_{0}(t), & \text { if } t \neq t_{k}\end{cases}
$$

Such class of processes allows investors to play a pure strategy $\left(v_{0}\right)$, play mixed strategy with positive weights of mixing ( $\xi$ 's), and play a mixed strategy with positive rates of mixing $\left(v_{j}\right.$ for $\left.j \geq 1\right)$.

The private offers condition is satisfied since the Poisson processes have deterministic intensities and $\xi$ 's are independent. The anonymity condition holds by construction due to independence of distributions $F_{\xi}$ 's, times of mixing $t_{k}$ 's, intensities of mixing $\lambda_{N_{j}}$ 's, and offered prices $v_{j}$ 's on the identity of the entrepreneur $i$. 


\section{B Proofs}

Proof of Lemma 1. Consider any equilibrium and denote $W_{t}^{i}$ continuation value of entrepreneur $i$ present in the market at time $t$. Since investors do not observe previous offers and each entrepreneur is atomistic continuation value does not depend on the private history $\mathcal{H}_{t}^{i}$ (value of offers made before or at time $t$ ), it depends only of the type of the project $\theta^{i}$ and calendar time $t$. Thus, any offer $v$ with $B_{\theta}(v)$ above $W_{t}^{\theta}$ will be accepted by entrepreneur with $\theta$ theta quality project and any valuation $v$ with $B_{\theta}(v)$ below $W_{t}^{\theta}$ will be rejected.

Proof of Lemma 2. Recall that continuation value of entrepreneur with good quality project is given by

$$
W_{t}^{g}=\sup _{F} \mathrm{E}\left[S_{g}+\int_{t}^{\infty} e^{-(\rho+\delta)(\tau-t)}\left(B_{g}\left(V_{\tau}\right)-S_{g}\right) d F_{\tau} \mid \tau>t\right]
$$

Index $i$ can be omitted since continuation value, expected future valuations and, hence, time of funding do not depend on the identity of the seller. Denote by $F^{*}$ the cdf corresponding to the optimal timing of fund-raising by an entrepreneur with a bad project. Then the following chain of inequalities holds:

$$
\begin{aligned}
B_{g}(v)-W_{t}^{g} & =B_{g}(v)-\sup _{F} \mathrm{E}\left[S_{g}+\int_{t}^{\infty} e^{-(\rho+\delta)(\tau-t)}\left(B_{g}\left(V_{\tau}\right)-S_{g}\right) d F_{\tau} \mid \tau>t\right] \\
& \leq B_{g}(v)-\mathrm{E}\left[S_{g}+\int_{t}^{\infty} e^{-(\rho+\delta)(\tau-t)}\left(B_{g}\left(V_{\tau}\right)-S_{g}\right) d F_{\tau}^{*} \mid \tau^{*}>t\right] \\
& =\mathrm{E}\left[\int_{t}^{\infty} B_{g}(v)-e^{-(\rho+\delta)(\tau-t)} B_{g}\left(V_{\tau}\right)-S_{g}\left(1-e^{-(\rho+\delta)(\tau-t)}\right) d F_{\tau}^{*} \mid \tau^{*}>t\right] \\
& =\frac{X_{g}}{X_{b}} \mathrm{E}\left[\int_{t}^{\infty} B_{b}(v)-e^{-(\rho+\delta)(\tau-t)} B_{b}\left(V_{\tau}\right)-\frac{X_{b}}{X_{g}} S_{g}\left(1-e^{-(\rho+\delta)(\tau-t)}\right) d F_{\tau}^{*} \mid \tau^{*}>t\right] \\
& <\frac{X_{g}}{X_{b}} \mathrm{E}\left[\int_{t}^{\infty} B_{b}(v)-e^{-(\rho+\delta)(\tau-t)} B_{b}\left(V_{\tau}\right)-S_{b}\left(1-e^{-(\rho+\delta)(\tau-t)}\right) d F_{\tau}^{*} \mid \tau^{*}>t\right] \\
& =\frac{X_{g}}{X_{b}}\left(B_{b}(v)-\mathrm{E}\left[\int_{t}^{\infty} e^{-(\rho+\delta)(\tau-t)} B_{b}\left(V_{\tau}\right)+S_{b}\left(1-e^{-(\rho+\delta)(\tau-t)}\right) d F_{\tau}^{*} \mid \tau^{*}>t\right]\right) \\
& =\frac{X_{g}}{X_{b}}\left(B_{b}(v)-\sup _{F} \mathrm{E}\left[\int_{t}^{\infty} e^{-(\rho+\delta)(\tau-t)} B_{b}\left(V_{\tau}\right)+S_{b}\left(1-e^{-(\rho+\delta)(\tau-t)}\right) d F_{\tau} \mid \tau>t\right]\right) \\
& =\frac{X_{g}}{X_{b}}\left(B_{b}(v)-W_{t}^{b}\right) .
\end{aligned}
$$

The strict inequality follows from $S_{g} / X_{g}>S_{b} / X_{b}$ while the first inequality follows from the fact that $F^{*}$ could be a suboptimal strategy for an entrepreneur with a good project. 
Proof of Lemma 3. Suppose the contrary, i.e. that entrepreneur with good project quality accepts an offer $v$ with probability less than one. Since $W_{t}^{g}>W_{t}^{b}$ all entrepreneurs with bad projects will accept valuation $v$.

Zero profit condition implies that

$$
v=\frac{\delta_{X}}{\delta_{X}+r} E\left(X_{\theta^{i}} \mid V_{t}^{i}=v, \tau^{i}=t\right)<\frac{\delta_{X}}{\delta_{X}+r}\left(\pi_{t} X_{g}+\left(1-\pi_{t}\right) X_{b}\right) .
$$

Inequality above is precisely due to mixing of entrepreneurs with good projects.

Since entrepreneur with good project type is indifferent between accepting and not

$$
W_{t}^{g}=B_{g}(v)<B_{g}\left(\frac{\delta_{X}}{\delta_{X}+r}\left(\pi_{t} X_{g}+\left(1-\pi_{t}\right) X_{b}\right)\right)
$$

Which violates Market Clearing condition.

Proof of Corollary 1. Easily follows from Lemmas 1-3 and Zero Profit condition.

Proof of Proposition 1 . In the steady state equilibrium average quality of the assets in the market $\pi_{t}$ is constant over time, which implies that $\pi_{t}$ can never be below the proportion of good project entering the market.

Suppose that $\pi_{t}>\hat{\pi}$. If it takes time to raise funds at a pooling valuation, then Market Clearing condition is violated since

$$
W_{t}^{g}<B_{g}\left(\frac{\delta_{X}}{\delta_{X}+r}\left(\pi_{t} X_{g}+\left(1-\pi_{t}\right) X_{b}\right)\right)
$$

If there exists a steady state equilibrium with $\pi_{t}>\hat{\pi}$ then it has to feature immediate acceptance of pooling offer. Since $\pi_{t} \geq 1 /(1+G(c))$ the unique equilibrium with $1 /(1+$ $G(c))>\hat{\pi}$ features immediate pooling.

Suppose that $\pi_{t}<\hat{\pi}$. This implies that entrepreneurs with good projects never invest prior to information arrival, i.e. $W_{t}^{g}=S_{g}$. But

$$
S_{g}=B_{g}\left(\frac{\delta_{X}}{\delta_{X}+r}\left(\hat{\pi}_{t} X_{g}+\left(1-\hat{\pi}_{t}\right) X_{b}\right)\right)<B_{g}\left(\frac{\delta_{X}}{\delta_{X}+r}\left(\pi_{t} X_{g}+\left(1-\pi_{t}\right) X_{b}\right)\right)
$$

which violates Market Clearing condition. Thus, $\pi_{t}<\hat{\pi}$ is impossible.

When $1 /(1+G(c))<\hat{\pi}$ the only possibility for $\pi_{t}$ is to be equal to $\hat{\pi}$. In order for $\pi_{t}$ to stay constant separating offer has to be accepted, hence $W_{t}^{b}=S_{b}$. Pooling offers need to be accepted as well, otherwise $\pi_{t}=1$, thus $W_{t}^{g}=B_{g}\left(\frac{\delta_{X}}{\delta_{X}+r}\left(\hat{\pi}_{t} X_{g}+\left(1-\hat{\pi}_{t}\right) X_{b}\right)\right)$. 
In order to keep $W_{t}^{g}$ and $W_{t}^{b}$ constant expected time to observing a pooling offer for individual entrepreneur has to be constant over time, i.e. distribution has to be memoryless. Exponential distribution is the only one satisfying this condition. Pooling offer arrives with intensity $\lambda_{p}$ which solves

$$
\left(\rho+\lambda_{p}\right) B_{b}\left(\frac{\delta_{X}}{\delta_{X}+r} X_{b}\right)=\lambda_{p} B_{b}\left(\frac{\delta_{X}}{\delta_{X}+r}\left(\hat{\pi}_{t} X_{g}+\left(1-\hat{\pi}_{t}\right) X_{b}\right)\right)
$$

Continuum of equilibria with $1 /(1+G(c))=\hat{\pi}$ can be constructed in the following way: pick any $\lambda>\lambda_{p}$ and put it to be the intensity of arrival of pooling offer for each entrepreneur, otherwise only separating offers are made. This price path together with entrepreneurs accepting offers no worse than the pooling one and entrepreneurs accepting offers only better than separating ones constitutes an equilibrium.

Proof of Proposition 2. First notice that $B_{b}(\alpha)$ is continuous and decreasing in $\alpha$ with

$$
\frac{1}{1+G\left(B_{b}(0)\right)}>0 \quad \frac{1}{1+G\left(B_{b}(1)\right)}<1
$$

hence there exists a unique $\tilde{\alpha}$ that solves $1 /\left(1+G\left(B_{b}(\alpha)\right)\right)=\alpha$.

If $\tilde{\alpha}>\hat{\pi}$, then $\alpha^{*}=\tilde{\alpha}$ and uniqueness of equilibrium is guaranteed by Proposition 1 .

If $\tilde{\alpha}<\hat{\pi}$ and $1 /\left(1+G\left(B_{b}(0)\right)\right)<\hat{\pi}$, then $\alpha^{*}=1 /\left(1+G\left(B_{b}(0)\right)\right)$ and uniqueness of equilibrium is guaranteed by Proposition 1.

Otherwise $\alpha^{*}=\hat{\pi}$. Continuation value of entrepreneurs with low quality assets solves

$$
\frac{1}{1+G\left(W_{t}^{b}\right)}=\hat{\pi}
$$

which pins down the arrival rate of the pooling offer $\lambda$ :

$$
\left(\lambda+\delta_{I}+\rho\right) W_{t}^{b}=\delta_{I} B_{b}(0)+\lambda B_{b}(\hat{\pi})
$$

Proof of Proposition 4. With a increase in $r$ the lemons condition threshold $\hat{\pi}$ is increasing, moreover, the whole curve $f(\pi)=\frac{1}{1+G\left(B_{b}(\pi)\right)}$ shifts up since for fixed $\pi B_{b}(\pi)$ is decreasing in $r$. 
Proof of Proposition 5. When $I\left(\frac{X_{g}}{X_{b}}-1\right)<\frac{\rho}{\delta \rho}\left(X_{g}-I\right)$ then $\hat{\pi}$ that solves (14) is negative for $r=0$, implying that lemons condition is not binding regardless of the market belief. Proposition 2 ensures that the unique equilibrium in this case is immediate pooling and a fraction of good projects entering the market $\alpha_{r=0}^{*}$ is positive. Put $\underline{r}$ to be a solution of

$$
\left.\hat{\pi}\right|_{r=\underline{r}}=\left.\alpha^{*}\right|_{r=0}
$$

Then for all $r<\underline{r}$ lemons condition threshold $\left.\hat{\pi}\right|_{r}<\left.\hat{\pi}\right|_{r=\underline{r}}=\left.\alpha^{*}\right|_{r=0}<\left.\alpha^{*}\right|_{r}$.

If $\frac{\rho}{\delta+\rho}\left(\frac{\delta_{X}}{\delta_{X}+\rho} X_{g}-I\right)<I\left(\frac{X_{g}}{X_{b}}-1\right)$ then $\left.\hat{\pi}\right|_{r=\rho} \in(0,1)$. Additionally, the restriction on $G$ implies that $\left.\alpha^{*}\right|_{r=\rho}$ is strictly below $\left.\hat{\pi}\right|_{r=\rho}$. Define $\bar{r}$ as a solution to

$$
\left.\hat{\pi}\right|_{r=\bar{r}}=\left.\alpha^{*}\right|_{r=\rho} .
$$

Clearly $0<\underline{r}<\bar{r}<\rho$ and for all $r \in(\bar{r}, \rho)$ the following chain of inequalities holds $\left.\alpha^{*}\right|_{r}<\left.\alpha^{*}\right|_{r=\rho}=\left.\hat{\pi}\right|_{r=\bar{r}}<\left.\hat{\pi}\right|_{r}$ since both $\alpha^{*}$ and $\hat{\pi}$ are strictly increasing in $r$.

Proof of Proposition 6 . Assume that in times when $Y_{t}=1$ there is immediate acceptance of the pooling offer, hence, continuation values for entrepreneurs seeking funding is

$$
W_{t}^{g}(1)=B_{g}\left(D_{X}(1)\left(\alpha_{1}^{*} X_{g}+\left(1-\alpha_{1}^{*}\right) X_{b}\right)\right) \quad W_{t}^{b}(1)=B_{b}\left(D_{X}(1)\left(\alpha_{1}^{*} X_{g}+\left(1-\alpha_{1}^{*}\right) X_{b}\right)\right) .
$$

And suppose that in times $Y_{t}=0$ pooling valuation $D_{X}(1)\left(\pi^{*} X_{g}+\left(1-\pi^{*}\right) X_{b}\right)$ arrives with intensity $\lambda_{p}$. Partial pooling outcome implies continuation values are given by

$$
W_{t}^{b}(0)=B_{b}\left(D_{X}(0) X_{g}\right) \quad W_{t}^{g}(0)=B_{g}\left(D_{X}(0)\left(\pi^{*} X_{g}+\left(1-\pi^{*}\right) X_{b}\right)\right)
$$

I will now prove that for sufficiently small $\lambda_{1}$ this can be sustained as an equilibrium. First define $\pi^{*}$ as a solution to

$$
\left(\rho+\lambda^{1}+\delta\right) B_{g}\left(D_{X}(0)\left(\pi^{*} X_{g}+\left(1-\pi^{*}\right) X_{b}\right)\right)=\lambda^{1} B_{g}\left(D_{X}(1)\left(\pi^{*} X_{g}+\left(1-\pi^{*}\right) X_{b}\right)\right)+\delta B_{g}\left(V_{g}\right)
$$

For small $\lambda^{1}$ the solution $\pi^{*}$ is well defined (i.e. it is less than 1), moreover, if $\lambda^{1}=0$ then $\pi^{*}=\left.\alpha^{*}\right|_{r=r(0)}$, otherwise $\pi^{*}>\left.\alpha^{*}\right|_{r=r(0)}$. Now, define $\lambda_{p}$ as a solution to

$$
\left(\rho+\lambda^{1}+\lambda_{p}\right) B_{b}\left(V_{b}\right)=\lambda^{1} B_{b}\left(D_{X}(1)\left(\pi^{*} X_{g}+\left(1-\pi^{*}\right) X_{b}\right)\right)+\lambda_{p} B_{b}\left(D_{X}(0)\left(\pi^{*} X_{g}+\left(1-\pi^{*}\right) X_{b}\right)\right) .
$$


Existence of $\lambda_{p}>0$ for small $\lambda^{1}$ is guaranteed by the fact that $\left.\hat{\pi}\right|_{r=r(0)}>\left.\alpha^{*}\right|_{r=r(0)}$. These two equation make sure that in the state $Y_{t}=0$ pooling offer is accepted by entrepreneurs with good and bad projects and entrepreneurs with bad projects are indifferent between waiting for a pooling valuation (or information revelation) and accepting a separating offer immediately. Clearly Zero Profit and Market Clearing condition is satisfied in this state.

I now need to make sure that immediate pooling is equilibrium in state $Y_{t}=1$, given the continuation values for state $Y_{t}=0$. Since the price of pooling is not moving over time, the only potentially profitable deviation for entrepreneurs is wait all the way until $Y_{t}=0$. This yields expected payoff

$$
\frac{\delta}{\delta+\lambda_{0}+\rho} B_{g}\left(V_{b}\right)+\frac{\lambda_{0}}{\delta+\lambda_{0}+\rho} W_{t}^{g}(0) \quad \text { and } \quad \frac{\delta}{\delta+\lambda_{0}+\rho} B_{b}\left(V_{b}\right)+\frac{\lambda_{0}}{\delta+\lambda_{0}+\rho} W_{t}^{b}(0)
$$

for the entrepreneurs with good and bad projects respectively. Conjectured $W_{t}^{b}(1)$ is higher than the pay-off from such deviation since is it higher component-wise. When $\lambda^{1}=0$ then $W_{t}^{g}(0)$ simply becomes $\delta /(\delta+\rho) B_{g}\left(D_{X}(1) X_{g}\right)$, hence the pay-off to deviation for the owner of the good project is less than $\delta /(\delta+\rho) B_{g}\left(V_{g}\right)$. Since $\left.\alpha^{*}\right|_{r=r(1)}>\left.\hat{\pi}\right|_{r=r(1)}$ the following inequality must hold

$$
W_{t}^{g}(1)=B_{g}\left(D_{X}(1)\left(\alpha_{1}^{*} X_{g}+\left(1-\alpha_{1}^{*}\right) X_{b}\right)\right)>\frac{\delta}{\delta+\rho} B_{g}\left(D_{X}(1) X_{b}\right),
$$

implying that $W_{t}^{g}(1)$ is still higher then the pay-off from deviation from sufficiently small $\lambda^{1}$. Zero Profit and Market Clearing conditions are trivially satisfied in $Y_{t}=1$ given the $W_{t}^{\theta}(1)$.

Proof of Propositions 8, 7, and 9. The entry threshold $c_{t}$ is determined by

$$
c_{t} \equiv c_{1}^{*}=B_{b}\left(D_{X}(1)\left(\alpha_{1}^{*} X_{g}+\left(1-\alpha_{1}^{*}\right) X_{b}\right)\right) \quad \text { when } Y_{t}=1
$$

and

$$
c_{t} \equiv c_{0}^{*}=B_{b}\left(D_{X}(0) X_{b}\right) \quad \text { when } Y_{t}=0 .
$$

Clearly, $c_{0}^{*}<c_{1}^{*}$ since $D_{X}(0)<D_{X}(1)$ and $\alpha_{1}^{*} \in(0,1)$, implying that quality of entry is worse in the $Y_{t}=1$ state.

When the state lasts for sufficiently long, the the average quality of funded projects is close to the average quality of projects entering the market, implying the statement of Proposition 8. 
When $Y_{t}=0$ funds are raised at both pooling and separating valuations. Denote by $q_{t}^{0}$ and $q_{t}^{\pi}$ rates of fund-raising at separating and pooling valuations respectively, then

$$
\dot{m}_{t}^{g}=1-q_{t}^{\pi} \cdot \pi_{t} \quad \dot{m}_{t}^{b}=G\left(c_{t}\right)-q_{t}^{\pi} \cdot\left(1-\pi_{t}\right)-q_{t}^{0} \quad \text { when } Y_{t}=0
$$

Since $\pi_{t}$ is equal to $\pi^{*}$ when $Y_{t}=0, G\left(c_{t}\right)-q_{t}^{0}=\frac{1-\pi_{t}}{\pi_{t}}$. Each entrepreneur $i$ raises funds at the pooling valuation with intensity $\lambda_{p}$, thus, the rate of deals at this valuation is $q_{t}^{\pi}=$ $\lambda_{p}\left(m_{t}^{g}+m_{t}^{b}\right)$. Plugging the values for $q_{t}^{0}$ and $q_{t}^{\pi}$ reveals that

$$
\dot{m}_{t}^{g}=1-\lambda_{p} m_{t}^{g}>0 \quad \dot{m}_{t}^{b}=\frac{1-\pi^{*}}{\pi^{*}}-\lambda_{p} m_{t}^{b}>0 \quad \text { when } Y_{t}=0
$$

implying that there is accumulation of unfunded projects in the market over time. When discount rate falls back to $r(1)$ immediate pooling implies at atom of deals,

The average quality of projects funded in the atom is $\pi^{*}$ which is higher than $\alpha_{0}^{*}$ by construction of equilibrium, hence, the statement of Proposition 7 follows.

Proof of Proposition 9 is given in the main text. 


\section{References}

Akerlof, George A., "The Market for "Lemons": Quality Uncertainty and the Market Mechanism," The Quarterly Journal of Economics, August 1970, 84 (3), 488-500.

Alti, Aydoğan, "IPO Market Timing," Review of Financial Studies, 2005, 18 (3), 11051138.

Axelson, Ulf, Tim Jenkinson, Per Strömberg, and Michael S Weisbach, "Leverage and Pricing in Buyouts: An Empirical Analysis," Working Paper, 2009.

Baker, Malcolm and Jeffrey Wurgler, "Market Timing and Capital Structure," The Journal of Finance, 2002, 57 (1), 1-32.

Ball, Eric, Hsin Hui Chiu, and Richard Smith, "Can VCs Time the Market? An Analysis of Exit Choice for Venture-backed Firms," Review of Financial Studies, 2011, 24 (9), 3105-3138.

Bustamante, M. Cecilia, "The Dynamics of Going Public," Review of Finance, 2012, 16 (2), 577-618.

Chang, Briana, "Adverse Selection and Liquidity Distortion in Decentralized Markets," Northwestern Mimeo, 2011.

Chang, Kiyoung, Yong-Cheol Kim, and Hyeongsop Shim, "Weak Firms Follow Strong Firms in Hot IPO Markets," Asia-Pacific Journal of Financial Studies, 2013, 42 (1), 76-108.

Chari, Varadarajan V, Ali Shourideh, and Ariel Zetlin-Jones, "Adverse Selection, Reputation and Sudden Collapses in Secondary Loan Markets," NBER Working Paper, 2010.

Choe, Hyuk, Ronald W. Masulis, and Vikram Nanda, "Common Stock Offerings Across the Business Cycle: Theory and Evidence," Journal of Empirical Finance, 1993, 1 (1), 3-31.

Daley, Brendan and Brett Green, "Waiting for News in the Market for Lemons," Econometrica, July 2012, 80 (4), 1433-1504. 
_ and _ , "An Information-based Theory of Time-varying Liquidity," Journal of Finance, Forthcoming.

Diller, Christian and Christoph Kaserer, "What Drives Private Equity Returns? Fund Inflows, Skilled GPs, and/or Risk?," European Financial Management, 2009, 15 (3), 643675.

Eisfeldt, Andrea L., "Endogenous Liquidity in Asset Markets," The Journal of Finance, 2004, 59 (1), 1-30.

Fuchs, William and Andrzej Skrzypacz, "Government Interventions in a Dynamic Market with Adverse Selection," Working Paper, 2014.

_, Aniko Öry, and Andrzej Skrzypacz, "Transparency and Distressed Sales under Asymmetric Information," Working Paper, 2014.

Gompers, Paul and Josh Lerner, "Money chasing deals? The impact of fund inflows on private equity valuation," Journal of Financial Economics, 2000, 55 (2), 281-325.

Guerrieri, Veronica and Robert Shimer, "Dynamic Adverse Selection: A Theory of Illiquidity, Fire Sales, and Flight to Quality," The American Economic Review, 2014, 104 (7), 1875-1908.

_ , _, and Randall Wright, "Adverse Selection in Competitive Search Equilibrium," Econometrica, November 2010, 78 (6), 1823-1862.

Horner, Johannes and Nicolas Vieille, "Public vs. Private Offers in the Market for Lemons," Econometrica, 2009, 77 (1), 29-69.

Kaplan, Steven N and Jeremy C Stein, "The Evolution of Buyout Pricing and Financial Structure in the 1980s," Quarterly Journal of Economics, 1993, 108, 313-357.

Kremer, Ilan and Andrzej Skrzypacz, "Dynamic signaling and market breakdown," Journal of Economic Theory, 2007, 133 (1), 58 - 82.

Kurlat, Pablo, "Lemons Markets and the Transmission of Aggregate Shocks," The American Economic Review, 2013, 103 (4), 1463-1489.

Nanda, Ramana and Matthew Rhodes-Kropf, "Investment Cycles and Startup Innovation," Journal of Financial Economics, 2013, 110 (2), 403 - 418. 
Noldeke, Georg and Eric Van Damme, "Signalling in a Dynamic Labour Market," The Review of Economic Studies, January 1990, 57 (1), 1-23.

Pagano, Marco, Fabio Panetta, and Luigi Zingales, "Why Do Companies Go Public? An Empirical Analysis," The Journal of Finance, 1998, 53 (1), 27-64.

Pástor, Ľuboš and Pietro Veronesi, "Rational IPO waves," The Journal of Finance, 2005, 60 (4), 1713-1757.

Ritter, Jay R and Ivo Welch, "A Review of IPO Activity, Pricing, and Allocations," The Journal of Finance, 2002, 57 (4), 1795-1828.

Strebulaev, Ilya, Haoxiang Zhu, and Pavel Zryumov, "Dynamic Information Asymmetry, Financing, and Investment Decisions," Working Paper, 2014.

Sun, Yeneng, "The exact law of large numbers via Fubini extension and characterization of insurable risks," Journal of Economic Theory, 2006, 126 (1), 31-69.

Swinkels, Jeroen M, "Education Signalling with Preemptive Offers," Review of Economic Studies, October 1999, 66 (4), 949-970.

Tirole, Jean, "Overcoming Adverse Selection: How Public Intervention Can Restore Market Functioning," The American Economic Review, 2012, 102 (1), 29-59.

Yung, Chris, Gönül Çolak, and Wang Wei, "Cycles in the IPO Market," Journal of Financial Economics, July 2008, 89 (1), 192-208. 